Article

\title{
A Glycosaminoglycan Extract from Portunus pelagicus Inhibits BACE1, the $\beta$ Secretase Implicated in Alzheimer's Disease
}

\author{
Courtney J. Mycroft-West ${ }^{1}$, Lynsay C. Cooper ${ }^{1}$, Anthony J. Devlin ${ }^{1,2}$, Patricia Procter ${ }^{1}$, \\ Scott E. Guimond ${ }^{1,3}{ }^{(D}$, Marco Guerrini ${ }^{2}$, David G. Fernig ${ }^{4}{ }^{(0)}$, Marcelo A. Lima ${ }^{1}$, \\ Edwin A. Yates ${ }^{1,4}$ and Mark A. Skidmore $1,3,4, *$ (D) \\ 1 Molecular \& Structural Biosciences, School of Life Sciences, Keele University, Huxley Building, Keele, \\ Staffordshire ST5 5BG, UK; c.j.mycroft-west@keele.ac.uk (C.J.M.-W.); 1.c.cooper@keele.ac.uk (L.C.C.); \\ a.devlin1@keele.ac.uk (A.J.D.); p.procter@keele.ac.uk (P.P.); s.e.guimond@keele.ac.uk (S.E.G.); \\ mlimagb@gmail.com (M.A.L.); E.A.Yates@liverpool.ac.uk (E.A.Y.) \\ 2 Istituto di Ricerche Chimiche e Biochimiche G. Ronzoni, Via G. Colombo 81, 20133 Milan, Italy; \\ guerrini@ronzoni.it \\ 3 Institute for Science and Technology in Medicine, Keele University, Keele, Staffordshire ST5 5BG, UK \\ 4 School of Biological Sciences, University of Liverpool, Crown Street, Liverpool L69 7ZB, UK; \\ dgfernig@liverpool.ac.uk \\ * Correspondence: m.a.skidmore@keele.ac.uk; Tel.: +44-(0)1782-733945
}

Received: 18 April 2019; Accepted: 9 May 2019; Published: 16 May 2019

\begin{abstract}
Therapeutic options for Alzheimer's disease, the most common form of dementia, are currently restricted to palliative treatments. The glycosaminoglycan heparin, widely used as a clinical anticoagulant, has previously been shown to inhibit the Alzheimer's disease-relevant $\beta$-secretase 1 (BACE1). Despite this, the deployment of pharmaceutical heparin for the treatment of Alzheimer's disease is largely precluded by its potent anticoagulant activity. Furthermore, ongoing concerns regarding the use of mammalian-sourced heparins, primarily due to prion diseases and religious beliefs hinder the deployment of alternative heparin-based therapeutics. A marine-derived, heparan sulphate-containing glycosaminoglycan extract, isolated from the crab Portunus pelagicus, was identified to inhibit human BACE1 with comparable bioactivity to that of mammalian heparin $\left(\mathrm{IC}_{50}=1.85 \mu \mathrm{g} \mathrm{mL}{ }^{-1}\left(\mathrm{R}^{2}=0.94\right)\right.$ and $2.43 \mu \mathrm{g} \mathrm{mL}{ }^{-1}\left(\mathrm{R}^{2}=0.93\right)$, respectively), while possessing highly attenuated anticoagulant activities. The results from several structural techniques suggest that the interactions between BACE1 and the extract from P. pelagicus are complex and distinct from those of heparin.
\end{abstract}

Keywords: Alzheimer's disease; amyloid- $\beta$; BACE1; $\beta$-secretase; glycosaminoglycan; heparan sulphate; heparin; Portunus pelagicus

\section{Introduction}

Alzheimer's disease (AD), the most common form of dementia, is characterized by progressive neurodegeneration and cognitive decline [1]. The deposition and aggregation of toxic amyloid- $\beta$ proteins $(A \beta)$, the primary constituents of $\beta$-amyloid plaques, has been identified as one of the primary causative factors in the development of AD. Approximately 270 mutations within genes that are directly associated with $\mathrm{A} \beta$ production are currently linked to the early-onset development of $\mathrm{AD}$ [2]. Furthermore, additional genetic risk factors for late-onset $\mathrm{AD}$ have been identified, most notably the APOE polymorphism [1]. Other pathological hallmarks of AD include the presence of intraneuronal neurofibrillary tangles (NFTs), an enhanced inflammatory response, neurotransmitter depletion, metal 
cation accumulation and oxidative stress [3]. In light of the above, the multifaceted nature of AD has dictated strategies that are capable of modulating the multiple, distinct pathophysiological pathways associated with AD [4].

Amyloid- $\beta$ peptides $(A \beta)$ are produced through the sequential cleavage of the type 1 transmembrane protein, amyloid precursor protein (APP). APP is initially cleaved by the aspartyl protease, $\beta$-site amyloid precursor protein cleaving enzyme 1 (BACE1), the primary neuronal $\beta$-secretase [5], liberating a soluble N-terminal fragment (sAPP $\beta$ ) and a membrane-bound C-terminal fragment ( $\beta$-CTF or C99). The $\beta$-CTF/C99 fragment subsequently undergoes cleavage by $\gamma$-secretase within the transmembrane domain, releasing a 36-43 amino acid peptide (A $\beta$ ) into the extracellular space; the most predominant species of $A \beta$ being $A \beta 40$ [6,7]. An imbalance favouring the production of $A \beta 42$ has been linked to the development of $A D$, owing to a higher propensity to oligomerize and form amyloid fibrils than the shorter $\mathrm{A} \beta 40$ [8].

As the rate-limiting step in $\mathrm{A} \beta$ production, $\mathrm{BACE} 1$ inhibition has emerged as a key drug target for the therapeutic intervention of the progression of $\mathrm{AD}$ in order to prevent the accumulation of toxic $A \beta[9,10]$. This is supported by the finding that BACE1-null transgenic mice models survive into adulthood with limited phenotypic abnormalities while exhibiting a reduction in brain $A \beta$ levels [5,11-16]. Despite the therapeutic potential of BACE1 inhibition, the successful development of clinically approved pharmaceuticals has proven a challenge due to the large substrate-binding cleft of BACE1, and unfavourable in vivo pharmaceutical properties of potent peptide inhibitors, for example, oral bioavailability, half-life and blood-brain barrier (BBB) penetration [10,17].

Heparan sulphate (HS), and its highly-sulphated analogue heparin (Hp), are members of the glycosaminoglycan (GAG) family of linear, anionic polysaccharides. They share a repeating disaccharide backbone consisting of a uronic acid (D-glucuronic acid; GlcA or L-iduronic acid; IdoA) and D-glucosamine, which can be variably sulphated or N-acetylated. HS is synthesised attached to core protein-forming HS proteoglycans (HSPGs), which have been identified co-localized with BACE1 on cell surfaces in the Golgi complex and in endosomes [18]. HSPGs were reported to endogenously regulate BACE1 activity in vivo through either a direct interaction with BACE1 and/or by sequestration of the substrate APP [18]. The addition of exogenous HS or heparin was also shown to inhibit BACE1 activity in vitro and reduced the production of $A \beta$ in cell culture [18-20]. Mouse models treated with low-molecular-weight heparin (LMWH) exhibit a reduction in A $\beta$ burden [21] and display improved cognition [22], although the multifaceted modes of heparin interaction (including inflammation, apolipoprotein E, metal interactions, [23], Tau, A $\beta$ and acetylcholinesterase) may present challenges when drawing definitive conclusions from in vivo mouse studies. That said, the ability of heparin to favourably modulate a multitude of potential AD-associated targets, beyond that of BACE-1 inhibition alone, would appear desirable. Furthermore, heparin oligosaccharides within the minimum size requirement for BACE1 inhibition $[18,19](<18$-mers) possess the ability to cross the blood-brain barrier (BBB) [24] and can be made orally bioavailable depending on formulation and encapsulation methods [25]. Heparin analogues, therefore, hold therapeutic potential as a treatment against AD, which may also offer an advantage over small molecule and peptide inhibitors of BACE1.

Heparin has been utilized clinically as a pharmaceutical anticoagulant for over a century due to its ability to perturb the coagulation cascade, principally through interactions with antithrombin III via the pentasaccharide sequence [-4) $\alpha$-D-GlcNS,6S (1-4) $\beta$-D-GlcA (1-4) $\alpha$-D-GlcNS,3S,6S (1-4) $\alpha$-L-IdoA2S (1-4) $\alpha$-D-GlcNS,6S (1-]. The side effect of anticoagulation presents as an important consideration when determining the potential of a heparin-based pharmaceutical for the treatment of AD. It has been previously determined that the anticoagulation potential of heparin can be highly attenuated by chemical modifications, while retaining the favourable ability to inhibit BACE1 [18-20]. Polysaccharides in which the 6-O-sulphate had been chemically removed were reported to have attenuated BACE1 activity $[18,19]$ although this correlates with an augmented rate of fibril formation [26].

Polysaccharides analogous to GAGs have been isolated from a number of marine invertebrate species that offer rich structural diversity and display highly attenuated anticoagulant activities 
compared to mammalian counterparts (for further detail, the reader is referred to the following reviews; $[27,28])$. The largely unexplored chemical diversity of marine-derived GAGs provides a vast reservoir for the discovery of novel bioactive compounds, some of which have been identified to exhibit antiviral [29,30], anti-parasitic [31,32], anti-inflammatory [33,34], anti-metastasis [35-37], anti-diabetic [38], anti-thrombotic [39] and neurite outgrowth-promoting activities [40]. Also, these compounds may be obtained from waste material, which makes their exploitation both economically and environmentally appealing. Here, a GAG extract isolated from the crab Portunus pelagicus has been found to possess attenuated anticoagulant activity while potently inhibiting the AD relevant $\beta$-secretase, BACE1, in vitro.

\section{Results}

\subsection{Isolation and Characterisation of a Glycosaminoglycan Extract from the Crab Portunus Pelagicus}

A glycosaminoglycan extract isolated from the crab Portunus pelagicus via proteolysis was fractionated by DEAE-Sephacel anion-exchange chromatography utilizing a stepwise sodium chloride gradient. The eluent at $1 \mathrm{M} \mathrm{NaCl}$ (fraction 5; designated P. pelagicus F5) was observed to have similar electrophoretic mobility in 1,3-diaminopropane buffer ( $\mathrm{pH}$ 9.0) to mammalian $\mathrm{HS} / \mathrm{Hp}$, with no bands observed corresponding to monosulphated chondroitin sulphate (CSA/CSC), disulphated chondroitin sulphate (CSD) or dermatan sulphate (DS) (Figure 1).

A

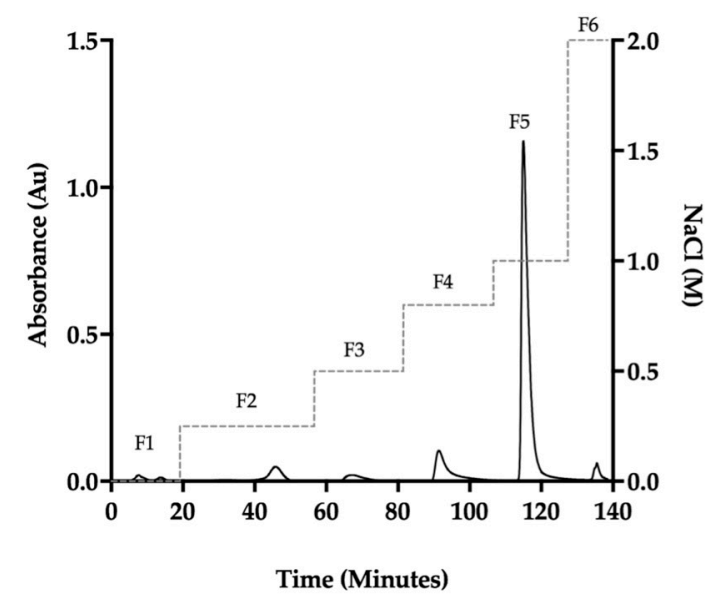

B

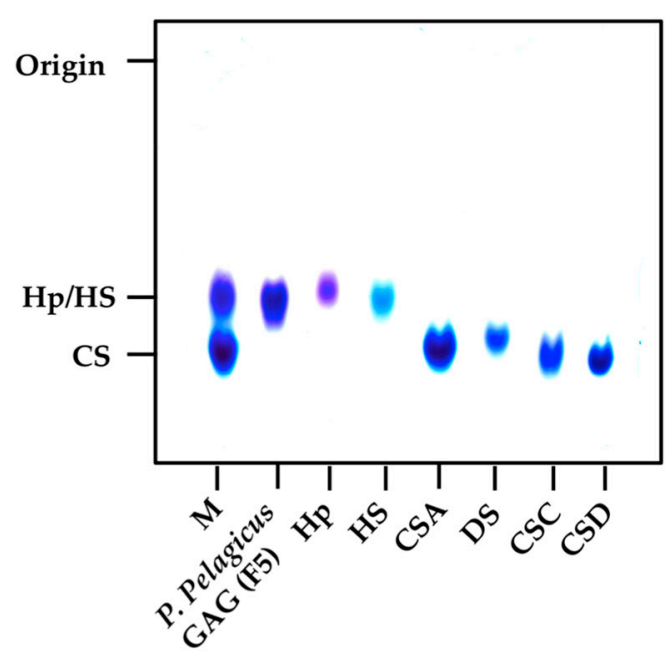

Figure 1. (A) DEAE purification of P. pelagicus crude glycosaminoglycan. Fractions 1-6 (F1-6; $\lambda_{\mathrm{Abs}}=232 \mathrm{~nm}$, solid line) were eluted using a stepwise $\mathrm{NaCl}$ gradient with HPAEC (dashed line). (B) Agarose gel electrophoresis of P. pelagicus F5. The electrophoretic mobility of P. pelagicus F5 was compared to that of bone fide glycosaminoglycan standards, heparin (Hp), heparan sulphate (HS), dermatan sulphate (DS) and chondroitin sulphate A, C and D (CSA, CSC and CSD, respectively). M: CSA, Hp and HS mixture.

In order to corroborate the Hp/HS like structural characteristics of P. pelagicus F5, the ATR-FTIR spectra has been compared with that of Hp. Both P. pelagicus F5 and Hp were shown to share similar spectral features, for instance bands at 1230, 1430 and $1635 \mathrm{~cm}^{-1}$, which are associated with $\mathrm{S}=\mathrm{O}$ stretches, symmetric carbonyl stretching and asymmetric stretches, respectively, indicative of common structural motifs. An additional peak and a peak shoulder located at $\sim 1750$ and $\sim 1370 \mathrm{~cm}^{-1}$ were observed in P. pelagicus F5, but absent in $\mathrm{Hp}$. The peak shoulder at $\sim 1370 \mathrm{~cm}^{-1}$ is indicative of a $\mathrm{Hp}$ and CS mixture. The differences observed between the spectra of P. pelagicus F5 and Hp in the variable 
OH region $\left(>3000 \mathrm{~cm}^{-1}\right)$ are likely to be associated with changeable moisture levels present during sample acquisition (Figure 2A) as opposed to underlying differences within the glycan structure [41].

Post-acquisition, the ATR-FTIR spectrum of P. pelagicus F5 was interrogated against a library of known GAGs comprising: $185 \mathrm{Hps}, 31 \mathrm{HSs}, 44 \mathrm{CSs}$ and DSs, 11 hyaluronic acids (HAs) and 6 oversulphated chondroitin sulphates (OSCSs) using principal component analysis (PCA; Figure 2B) [41]. Principal component 1 (PC1), which covers $57 \%$ of the total variance, indicates that $P$. pelagicus F5 locates within the region containing mammalian Hp/HS. Through comparison of PC1 and PC2, comprising $>70 \%$ of the total variance, P. pelagicus F5 lies towards the CS region, a location previously identified with Hps containing small amounts of CS/DS [41] analogous to crude, pharmaceutical Hp.

A

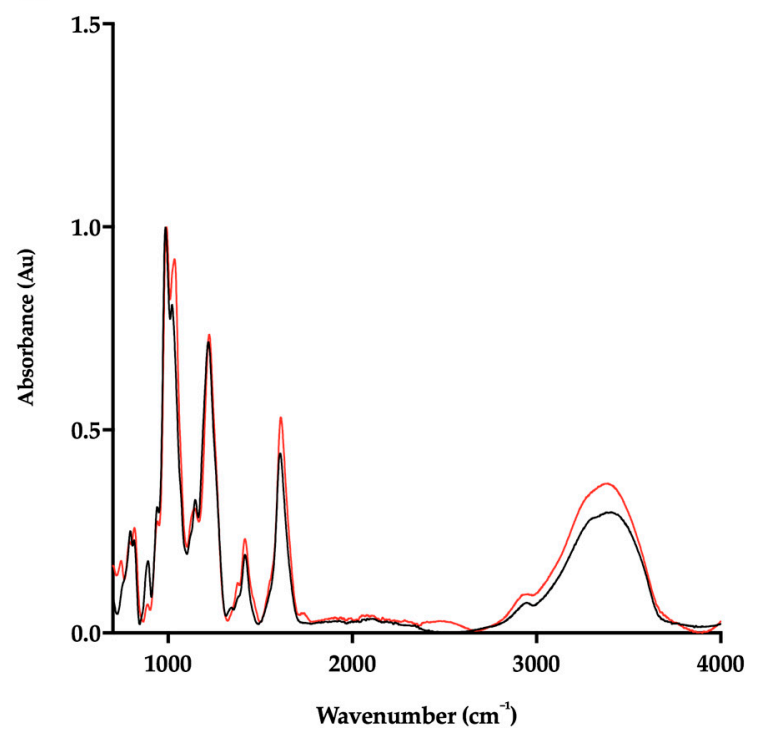

B

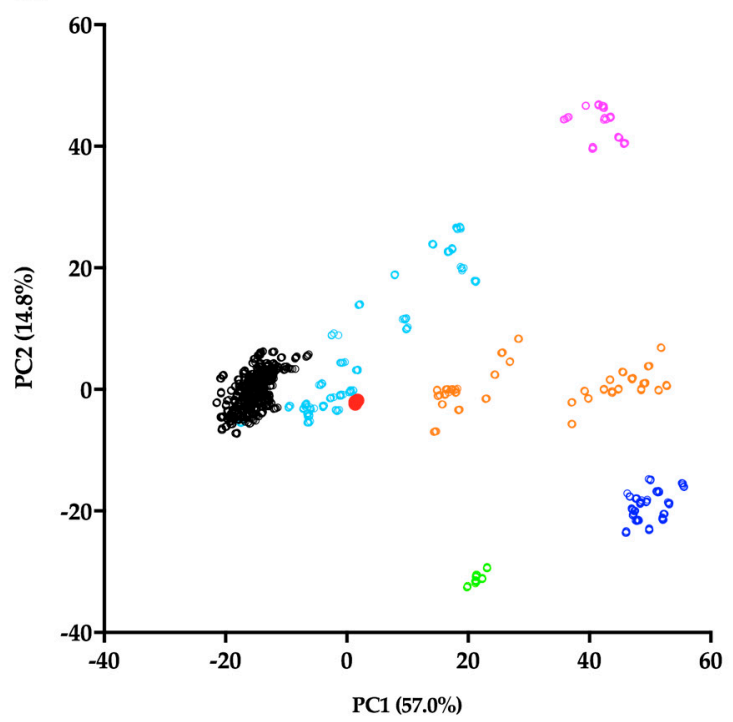

Figure 2. (A) ATR-FTIR spectra of porcine mucosal Hp (black) and P. pelagicus F5; (red), $\mathrm{n}=5$. (B) Principal component analysis (PCA) Score Plot for PC1 vs. PC2 of P. pelagicus F5 against a bone fide GAG library. Hp, black; HS, cyan; CS, orange; DS, blue; hyaluronic acid (HA), magenta; oversulphated-CS, light green and P. pelagicus F5, red (filled circle).

P. pelagicus F5 was subsequently subjected to exhaustive enzymatic cleavage with Flavobacterium heparinum lyases I, II and III. The digest products from Hp control (Figure 3, Table 1) and P. pelagicus F5 (Figure 4, Table 1), were analysed using strong anion-exchange chromatography and the retention times compared to those of the eight common $\Delta$-disaccharide standards present within both $\mathrm{Hp}$ and HS [42].

The digest products detected for Hp were in agreement with a typical mammalian Hp disaccharide profile [42], with $51.5 \%$ of the total products attributable to the trisulphated $\Delta-\mathrm{UA}(2 \mathrm{~S})$-GlcNS(6S) and $22.9 \%$ to $\Delta$-UA-GlcNS(6S). A minimal proportion of mono- or unsulphated disaccharides, accounting for 12.3 and $4.3 \%$, respectively, were also observed for $\mathrm{Hp}$. In comparison, a more disperse sulphation profile was observed for P. pelagicus F5 than Hp (Table 1), with a comparatively lower proportion of trisulphated disaccharides, $23.1 \%$. The P. pelagicus F5 contained $24.4 \%$ monosulphated disaccharides, of which $16.5 \%$ was accounted for by $\Delta-\mathrm{UA}(2 \mathrm{~S})$-GlcNAc. A higher proportion of $\Delta-\mathrm{UA}(2 \mathrm{~S})$-GlcNS $(23.5 \%)$ was also detected in P. pelagicus F5 than Hp (5.9\%), indicating that the compound displays distinct structural characteristics. Such features also contrast with that of HS, where $\sim 50-70 \%$ of disaccharides are comprised of $\Delta$-UA-GlcNAc/ $\Delta$-UA-GlcNS [42-45]. Also, P. pelagicus F5 presents a significant higher proportion of trisulphated disaccharides than commonly present in mammalian HS, a typical marker of more heparin-like structures. 


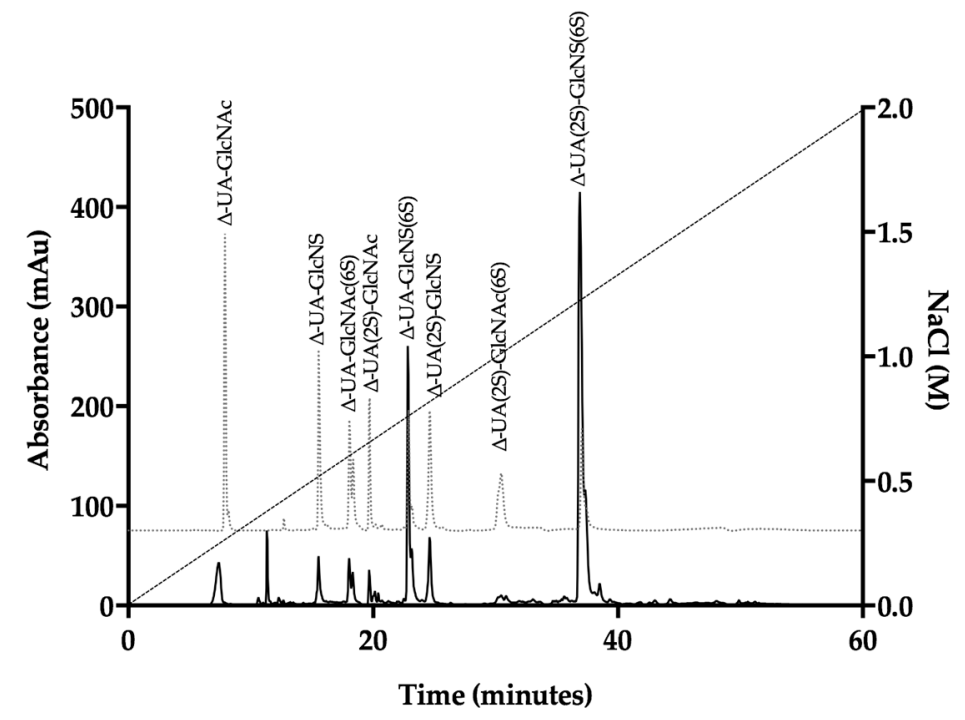

Figure 3. UV-SAX HPLC disaccharide composition analysis was performed on the bacterial lyase digest of $\mathrm{Hp}\left(\lambda_{\mathrm{Abs}}=232 \mathrm{~nm}\right)$ eluting with a linear gradient of $0-2 \mathrm{M} \mathrm{NaCl}$ (dashed line). Eluted $\Delta$-disaccharides were referenced against the eight common standards present within Hp and HS (light grey, dotted line).

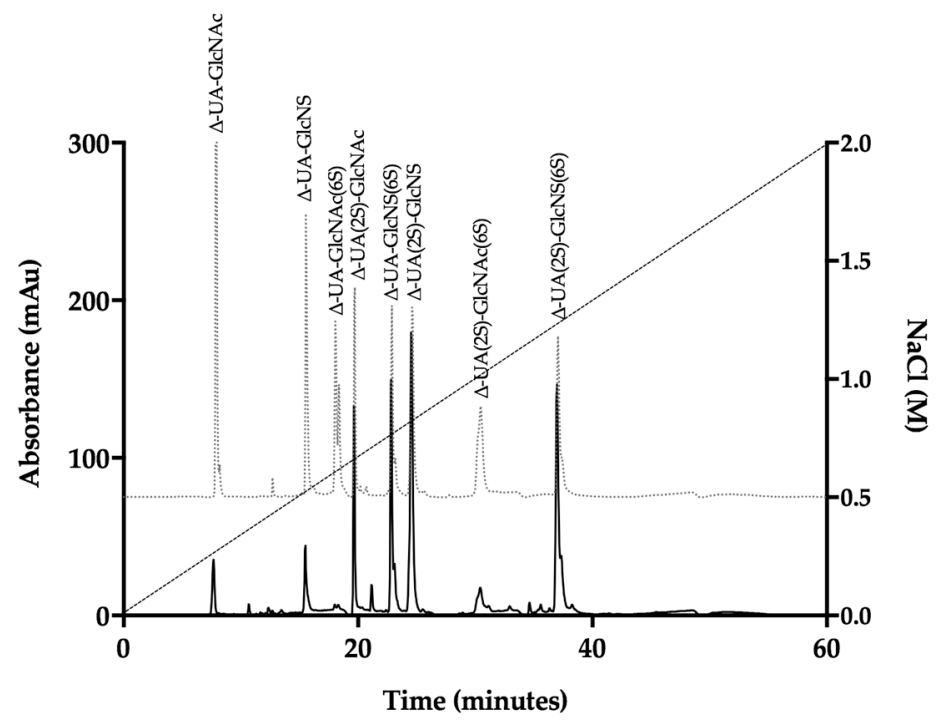

Figure 4. UV-SAX HPLC disaccharide composition analysis was performed on the bacterial lyase digest of the P.pelagicus F5 $\left(\lambda_{\mathrm{Abs}}=232 \mathrm{~nm}\right)$, eluting with a linear gradient of $0-2 \mathrm{M} \mathrm{NaCl}$ (dashed line). Eluted $\Delta$-disaccharides were referenced against the eight common standards present within Hp and HS (light grey, dotted line).

Table 1. Corrected disaccharide composition analysis of P. pelagicus F5 and Hp.

\begin{tabular}{|c|c|c|}
\hline$\Delta$-Disaccharide & P. pelagicus F5 (\%) & Hр (\%) \\
\hline$\Delta$-UA-GlcNAc & 2.8 & 4.3 \\
\hline$\Delta$-UA-GlcNS & 5.6 & 4.2 \\
\hline$\Delta$-UA-GlcNAc(6S) & 2.3 & 5.0 \\
\hline$\Delta$-UA(2S)-GlcNAc & 16.5 & 3.1 \\
\hline$\Delta$-UA-GlcNS(6S) & 20.2 & 22.9 \\
\hline$\Delta$-UA(2S)-GlcNS & 23.5 & 5.9 \\
\hline$\Delta$-UA(2S)-GlcNAc(6S) & 6.0 & 3.1 \\
\hline$\Delta$-UAs(2S)-GlcNS(6S) & 23.1 & 51.5 \\
\hline
\end{tabular}


Proton and Heteronuclear Single-Quantum Correlation (HSQC) NMR was employed to confirm the GAGs composition of P. pelagicus F5. ${ }^{1} \mathrm{H}$ NMR can indicate the major signals associated with $\mathrm{HS}$ as well as signals that arise from galactosaminoglycans such as CS. The presence of both (Figure 5A insert) is easily identified by the two $\mathrm{N}$-acetyl signals at $2.02 \mathrm{ppm}$ (CS) and $2.04 \mathrm{ppm}(\mathrm{HS}) .{ }^{1} \mathrm{H}-{ }^{13} \mathrm{C}$ HSQC NMR (Figure 5B) has been used to resolve overlapping signals and saccharide composition estimates using peak volume integration. The integration of $\mathrm{N}$-acetyl signals revealed that the extract is composed of approximately $60 \% \mathrm{HS}$ and $40 \%$ CS. The combined integration of the N-acetyl and A2 signals from the HS showed that $P$. pelagicus F5 possesses a high NS content of approximately $76 \%$, which supports the HPLC-based empirical disaccharide analysis (Figure 4 and Table 1). Together, this data establishes that the HS of P. pelagicus F5 is considerably more sulphated (Table 1) than that commonly extracted from mammalian sources [45]. With regard to the CS element of P. pelagicus F5, signals typical of the CS backbone are present although sulhation is generally low, with galactosamine 6-O-sulphation occurring in approximately $35 \%$ of all CS residues. The lack of non-overlapping signals for galactosamine 4-O-sulphation indicates that all but negligible levels of such a modification are present within the CS component.

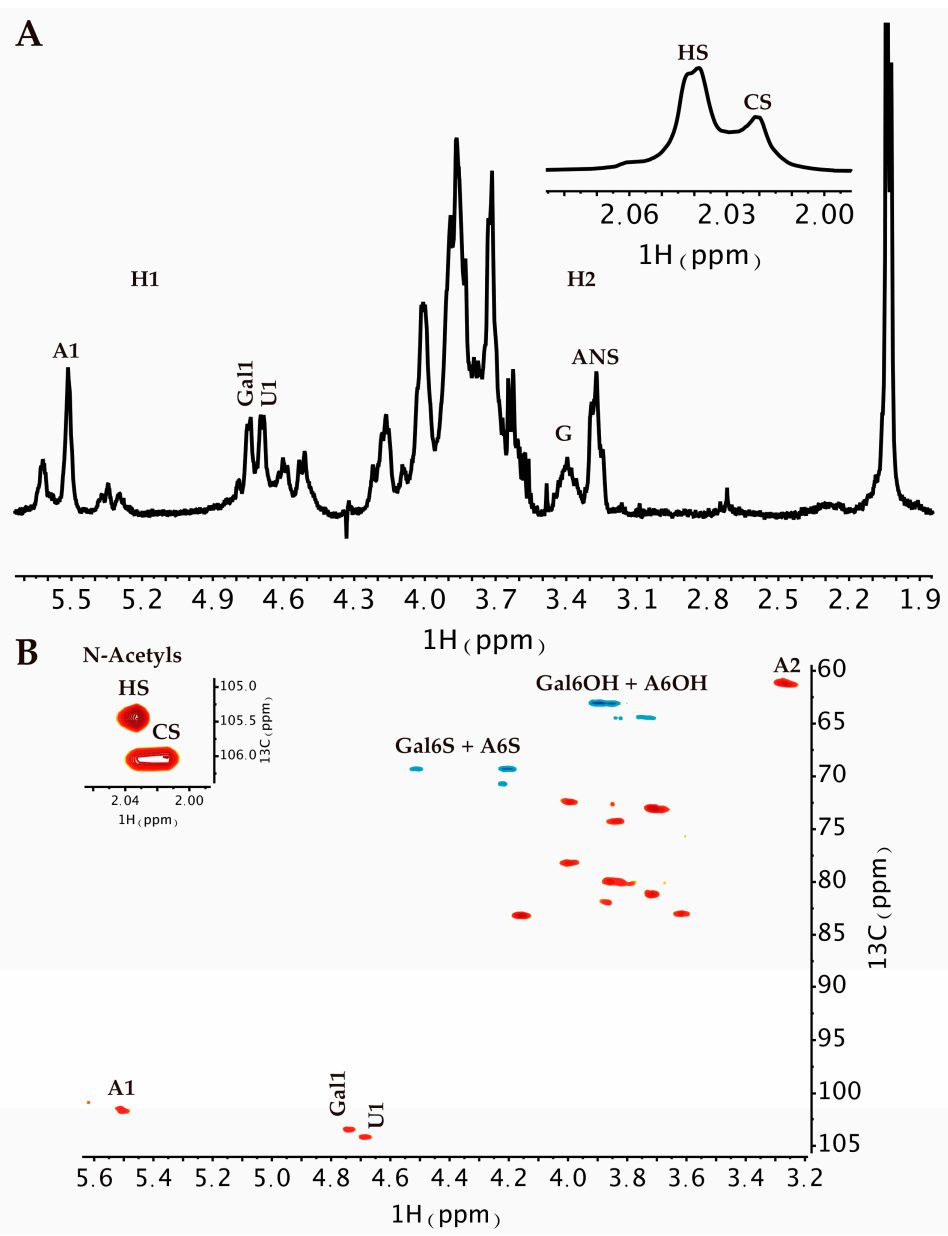

Figure 5. (A) ${ }^{1} \mathrm{H}$ and (B) ${ }^{1} \mathrm{H}_{-}-{ }^{13} \mathrm{C}$ HSQC NMR spectra of P. pelagicus F5. Major signals associated with HS and CS are indicated. Spectral integration was performed on the HSQC using labelled signals. Key: glucosamine, A; uronic acid, U; N-Acetyl, Nac and galactosamine, Gal.

\subsection{P. pelagicus F5 Inhibits the Alzheimer's Disease-Relevant $\beta$-Secretase 1}

P. pelagicus F5 was assayed for inhibitory potential against BACE1, utilizing a fluorogenic peptide cleavage FRET assay, based on the APP Swedish mutation. Reactions were performed at $\mathrm{pH}$ 4.0, within the optimal $\mathrm{pH}$ range for BACE1 activity (Figure 6). A maximal level of BACE1 inhibition of 
$90.7 \pm 2.9 \%(\mathrm{n}=3)$ was observed in the presence of $5 \mu \mathrm{g} \mathrm{mL}{ }^{-1}$ P. pelagicus $\mathrm{F} 5$, with an $\mathrm{IC}_{50}$ value of $1.9 \mu \mathrm{g} \mathrm{mL}^{-1}\left(\mathrm{R}^{2}=0.94\right)$. This was comparable to the activity of $\mathrm{Hp}$, which exhibited a maximal level of BACE1 inhibition of $92.5 \pm 1.5 \%(\mathrm{n}=3)$ at $5 \mu \mathrm{g} \mathrm{mL} \mathrm{L}^{-1}$, with an $\mathrm{IC}_{50}$ of $2.4 \mu \mathrm{g} \mathrm{mL} \mathrm{m}^{-1}\left(\mathrm{R}^{2}=0.93\right)$.

In the presence of low concentrations of $\mathrm{Hp}$, an increase in BACE1 activity was observed (Figure 6A,B), with maximal activation occurring at $625 \mathrm{ng} \mathrm{mL}^{-1}(57.5 \pm 3.7 \%, \mathrm{n}=3)$. The BACE1 utilised in this study consisted of the zymogen form $\left(\mathrm{Thr}^{22}-\mathrm{Thr}^{457}\right)$, containing the prodomain sequence. This is in accordance with previous reports that demonstrate low concentrations $\left(\sim 1 \mu \mathrm{g} \mathrm{mL} \mathrm{m}^{-1}\right)$ of heparin can stimulate proBACE1 activity [46,47]. A maximum increase in BACE1 activity was also detected in the presence of $625 \mathrm{ng} \mathrm{mL}^{-1}$ of $P$. pelagicus $\mathrm{F} 5(38.5 \pm 1.4 \%, \mathrm{n}=3)$, although significantly diminished promotion was displayed compared to the same concentration of $\operatorname{Hp}(57.5 \pm 3.7 \%, \mathrm{n}=3)$; $\mathrm{t}(4)=4.859, p=0.0083$. This indicates that although P. pelagicus F5 exhibits stimulatory activity, it is significantly less than that of $\mathrm{Hp}$. The percent activity level returned to that of the negative control value at concentrations lower than $312.5 \mathrm{ng} \mathrm{mL}^{-1}$, indicating that both inhibitory and stimulatory effects are dose dependent. For both Hp and P. pelagicus F5, BACE1 promotion was followed by enzyme inhibition, as previously reported (Figure 6B,C; [47]). The rate of BACE1 activity between 60 and 90 min was significantly different from controls lacking either $\mathrm{Hp}(\mathrm{n}=3-6 ; \mathrm{t}(4)=7, p<0.003)$ or P. pelagicus F5 ( $\mathrm{n}=3-6 ; \mathrm{t}(6)=7, p<0.004)$ at $625 \mathrm{ng} \mathrm{mL}-1$, indicating that inhibition was not due to substrate limitations.

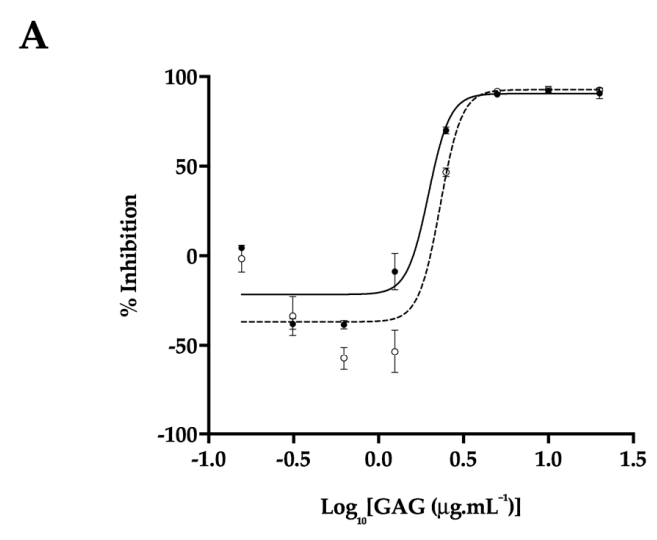

B

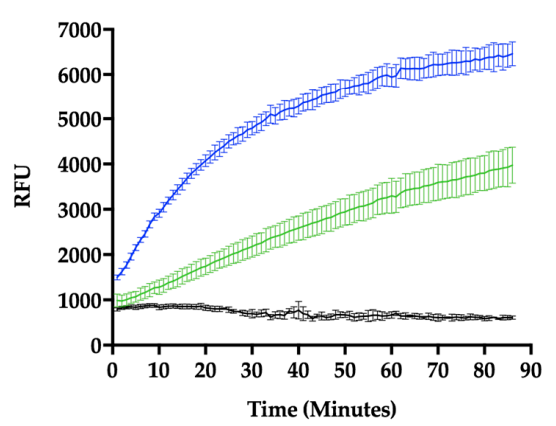

C

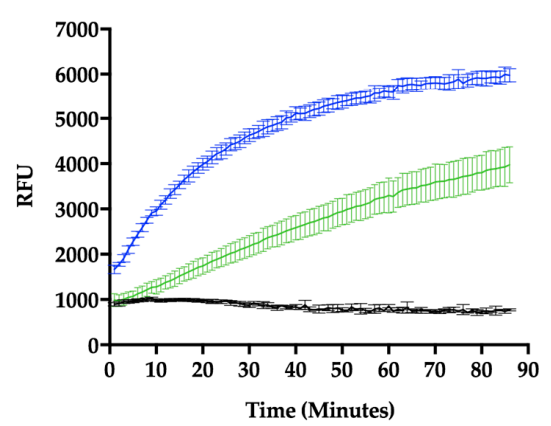

Figure 6. Inhibition of human BACE1 by Hp or P. pelagicus F5. (A) Dose response of Hp (dashed line, open circles) or P. pelagicus F5 (solid line, filled circles) as determined using FRET. P. pelagicus F5, $\left.\mathrm{IC}_{50}=1.9 \mu \mathrm{g} \mathrm{mL}{ }^{-1}\left(\mathrm{R}^{2}=0.94\right) ; \mathrm{Hp}, \mathrm{IC}_{50}=2.4 \mu \mathrm{g} \mathrm{mL}-1 \mathrm{R}^{2}=0.93\right)$. (B) Time-course activation or inhibition of BACE1 by $5 \mu \mathrm{g} \mathrm{mL}^{-1}$ (black) or $625 \mathrm{ng} \mathrm{mL}^{-1}$ (blue) $\mathrm{Hp}$, compared to water control (green). (C) The same as (B) for P. pelagicus F5.

\subsection{Heparin Binding Induces a Conformational Change in the Alzheimer's Disease $\beta$-Secretase, BACE1}

Hp binding has been proposed to occur at a location close to the active site of BACE1 [18], possibly within or adjacent to the prodomain sequence [46]. In light of the contrasting and 
concentration-dependant BACE1:GAG bioactivities, the ability of $\mathrm{Hp}$ and P. pelagicus F5 to induce structural changes in BACE1 has been investigated utilising circular dichroism (CD) spectroscopy at a range of $w / w$ ratios; this also negates the intrinsic effect of the significant polydispersity for this class of biomolecules.

The CD spectra of BACE1 at $\mathrm{pH} 4.0$ has previously been shown to contain a greater proportion of $\beta$-sheet and reduced $\alpha$-helical content, compared to spectra obtained at $\mathrm{pH} 7.4$, indicating that at an acidic $\mathrm{pH}$, where BACE1 is most active, a conformational change can be observed by CD [50]. Consistent with this, the CD spectra of BACE1 in $50 \mathrm{mM}$ sodium acetate buffer at $\mathrm{pH} 4.0$ (Figures 7 and 8) featured a positive peak at wavelengths below $200 \mathrm{~nm}$, which can be attributed to a sum of $\alpha$-helical and $\beta$-sheet structures [51]. The broad, negative band observed between wavelengths 250 and $200 \mathrm{~nm}$, contains a peak at $\lambda=218 \mathrm{~nm} \sim 208 \mathrm{~nm}$, commonly associated with antiparallel $\beta$-sheets and $\alpha$-helical structures, respectively [51] (Figures 7 and 8). The CD spectra of BACE1 at pH 4.0 can be estimated to have a secondary structural composition of $9 \% \alpha$-helix, 31\% antiparallel $\beta$-sheet, $16 \%$ turn and $44 \%$ other (NRMSD < 0.1) when fitted against a library of representative proteins using BeStSel [48]. This was in close agreement with the BestSel secondary structure prediction based on x-ray crystallography of BACE1 at pH 4.0 (PDB accession no 2ZHS, [52] of 7\% $\alpha$-helix, 30\% antiparallel, $4 \%$ parallel, $12 \%$ turn and $47 \%$ other). Deviations between secondary structure predictions may be accounted for by subtle differences present within the BACE1 primary sequences.

A

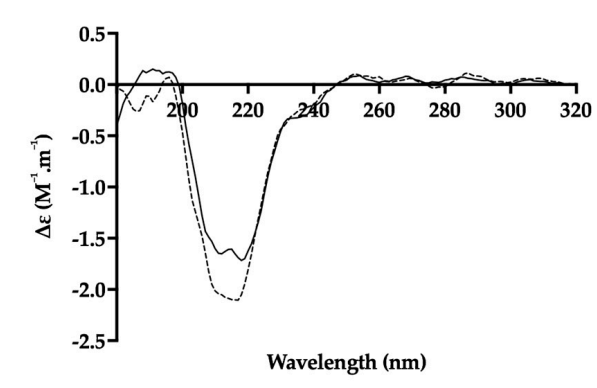

C

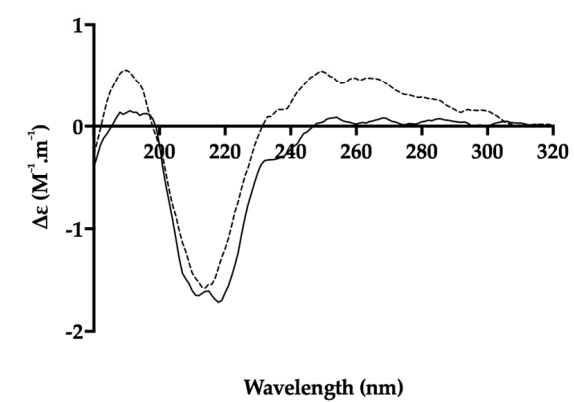

B

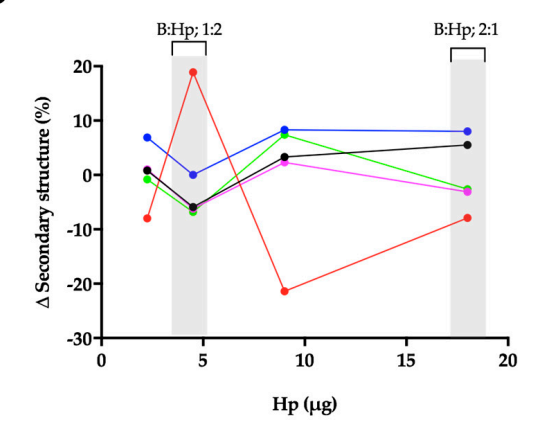

D

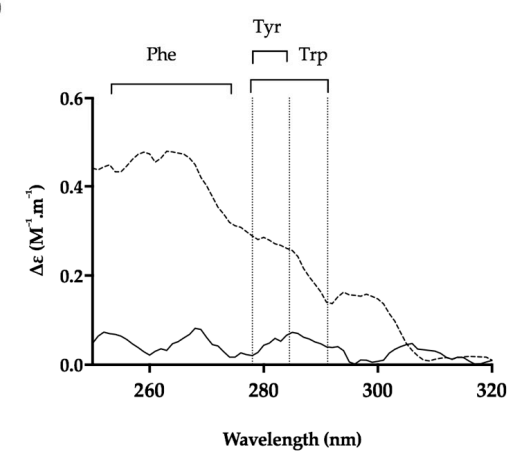

Figure 7. The structural change of BACE1 observed in the presence of Hp by circular dichroism (CD) spectroscopy. (A) CD spectra of BACE1 alone (solid line) or with Hp at a ratio of 1:2 (w/w; dashed line; B:Hp 1:2); (B) $\Delta$ secondary structure (\%) of BACE1 upon the addition of increasing amounts of Hp; $\alpha$-helix (black), antiparallel (red), parallel (blue), turn (magenta) and others (green) [48]. \% structural change of B:Hp; 1:2 or 2:1 (w/w) ratio are highlighted in grey. (C) CD spectra of BACE1 alone (solid line) with Hp (dashed line) at a ratio of 2:1 w/w (D) Near-UV CD spectra of (C); respective absorption regions of aromatic amino acids are indicated [49]. Spectra were recorded in $50 \mathrm{mM}$ sodium acetate buffer at $\mathrm{pH} 4.0$ in all panels.

In the presence of a BACE1:Hp (B:Hp), ratio of 1:2 $(w / w)$ where maximal inhibition was observed in FRET assays, the CD spectra of BACE1 exhibited increased negative ellipticity below $\lambda=222 \mathrm{~nm}$, 
resulting in an estimated increase in $\alpha$-helix $(+6 \%)$ and a reduction in antiparallel $\beta$-sheet $(-8 \%)$ (NRMSD < 0.1) [48] (Figure 7A,B). In comparison to Hp, BACE1 in the presence of P. pelagicus F5 (B:F5), at the same ratio $(1: 2 ; w / w)$, exhibited a slight increase in positive ellipticity between $\lambda=222-200 \mathrm{~nm}$ and decreases at $\lambda<200 \mathrm{~nm}$, resulting in an estimated change in $\alpha$-helical content of $+1 \%$ accompanied by a decrease in antiparallel $\beta$-sheet content of $8 \%$ (Figure $8 \mathrm{~A}, \mathrm{~B}$ ). This is in contrast to CD studies in the presence of peptide inhibitors, which did not reveal a secondary structural change in BACE1 [50].

The conformational change of BACE1 upon binding to $\mathrm{Hp}$ and P. pelagicus F5 was assessed over a range of ratios (Figures $7 \mathrm{~B}$ and $8 \mathrm{~B})$. At a $\mathrm{B}: \mathrm{Hp}$ ratio of 2:1 $(w / w)$, a change in the characteristics of the CD spectrum of BACE1 was observed in the far-UV region $(\lambda<250 \mathrm{~nm}$; Figure $7 \mathrm{C})$ that was identified as a reduction in $\alpha$-helix by $6 \%$ and an increase in antiparallel $\beta$-sheet structures $19 \%$ (NRMSD < 0.1) [48]. In addition, an increase in positive ellipticity was observed in the near-UV region (250-300 nm; Figure 7C,D) following the addition of Hp, which may be attributed to a change in the tertiary structure of BACE1 involving aromatic amino acids [49,53]. In contrast, B:F5 at the same ratio of 2:1 $(w / w)$, exhibited a decrease in ellipticity in the near- and far- UV region $(\lambda<300 \mathrm{~nm}$; Figure S1).

The increase in positive ellipticity observed in the CD spectra of BACE1 in the near-UV region at a B:Hp ratio of 2:1 (w/w) was also observed at a 1:1 $(w / w)$ ratio of B:F5 (Figure $8 C, D)$. The secondary structural change in the far-UV CD spectrum of BACE1 at a B:F5 ratio of 1:1 $(w / w)$ for $\lambda=250-190 \mathrm{~nm}$ corresponded to a decrease in $\alpha$-helix by $8 \%$ and an increase in antiparallel $\beta$-sheet structures by $15 \%$.

A

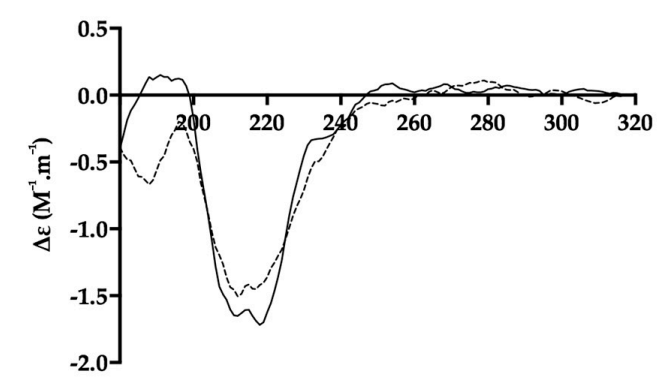

Wavelength (nm)

C

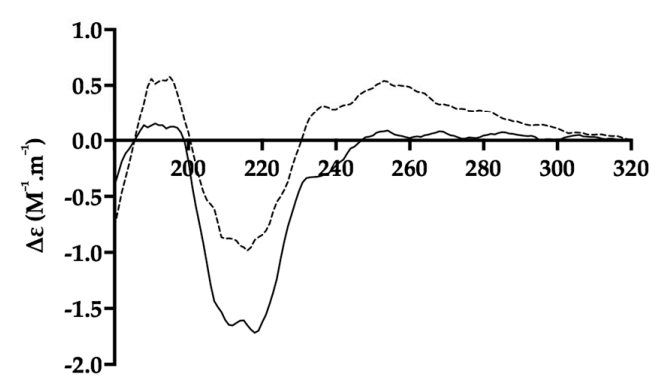

Wavelength (nm)
B

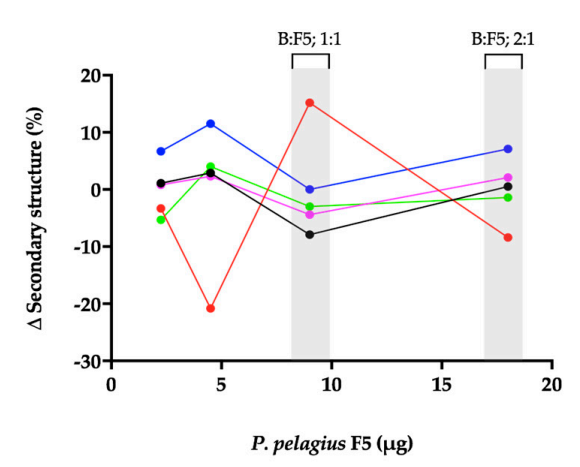

D

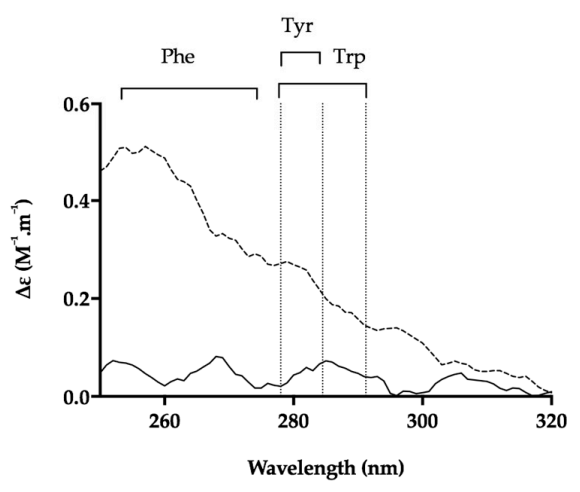

Figure 8. The structural change of BACE1 observed in the presence of P. pelagicus F5 by CD spectroscopy. (A) CD spectra of BACE1 alone (solid line) with P. pelagicus F5 (dashed line; ratio of 1:2 w/w; B:F5); (B) $\Delta$ secondary structure (\%) of BACE1 upon the addition of increasing amounts of $P$. pelagicus F5; $\alpha$-helix (black), antiparallel (red), parallel (blue), turn (magenta) and others (green) [48] \% structural change of B:F5; 1:2 or 1:1 ratio are highlighted in grey. (C) CD spectra of BACE1 alone (solid line) or with P. pelagicus F5 (dashed line; ratio of 1:1 w/w); (D) Near-UV CD spectra of (C); respective absorption regions of aromatic amino acids are indicated [49]. Spectra were recorded in $50 \mathrm{mM}$ sodium acetate buffer at $\mathrm{pH} 4.0$ in all panels. 


\subsection{Heparin and P. pelagicus F5 Destabilise the Alzheimer's Disease $\beta$-Secretase, BACE1}

Both $\mathrm{Hp}$ and P. pelagicus F5 were shown to induce a conformational change in BACE1, in contrast to previous $C D$ studies in the presence of peptide inhibitors [50]. Therefore, to explore whether the binding of $\mathrm{Hp}$ or P. pelagicus F5 alters the stability of BACE1 in a mechanism similar to known inhibitors, differential scanning fluorimetry (DSF) was employed to monitor the change in thermal stability. Previously identified BACE1 inhibitors have been shown to stabilize BACE1, exemplified by an increase in $\mathrm{T}_{M}$ values obtained through DSF measurements [54]. In the presence of a BACE1:Hp or P. pelagicus $\mathrm{F} 5$ ratio of $1: 2$, a decrease in the $\mathrm{T}_{\mathrm{M}}$ of $\mathrm{BACE} 1$ by $11^{\circ} \mathrm{C}$ and $10^{\circ} \mathrm{C}$, respectively was observed (Figure 9A). The change in $\mathrm{T}_{\mathrm{M}}$ of BACE1 induced by binding of either Hp or P. pelagicus $\mathrm{F} 5$ was not significantly different, $(\mathrm{p}=0.1161 \mathrm{t}=2 \mathrm{df}=4)$. The destabilisation of BACE1 in the presence of both Hp and P. pelagicus F5 was found to be concentration dependent (Figure 9B).

A

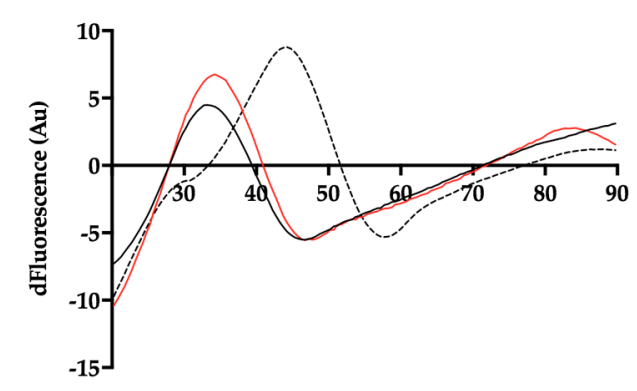

Temperature $\left({ }^{\circ} \mathrm{C}\right)$

\section{B}

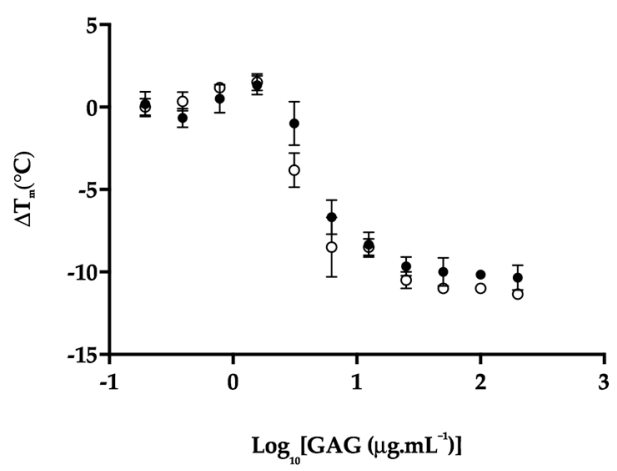

Figure 9. (A) First differential of the DSF thermal stability profile of BACE1 alone (1 $\mu$; dashed line), and with Hp ( $2 \mu \mathrm{g}$; black line) or P. pelagicus F5 ( $2 \mu \mathrm{g}$; red line) in $50 \mathrm{mM}$ sodium acetate, $\mathrm{pH} 4.0$; (B) $\Delta$ $\mathrm{T}_{\mathrm{m}}$ of BACE1 with increasing [Hp] or [P. pelagicus F5] (open or closed circles, respectively).

\subsection{Attenuated Anticoagulant Activities of the P. pelagicus Glycosaminoglycan Extract}

An important consideration when determining the therapeutic potential of a heparin-like polysaccharide against $\mathrm{AD}$ is the likely side effect of anticoagulation. The prothrombin time (PT) and activated partial thromboplastin time (aPTT) of P. pelagicus F5 were measured compared to Hp (193 IU mg ${ }^{-1}$ ), to determine the overall effect on the extrinsic and intrinsic coagulation pathways, respectively (both assays also include the common coagulation pathway). In comparison to Hp, P. pelagicus F5 exhibited reduced anticoagulant activity in both the PT (Figure 10A; EC 50 of $420.2 \mu \mathrm{g}$ $\mathrm{mL}^{-1}$ compared to $19.53 \mu \mathrm{g} \mathrm{mL}{ }^{-1}$, respectively) and aPTT (Figure 10B; $\mathrm{EC}_{50} 43.21 \mu \mathrm{g} \mathrm{mL}^{-1}$ compared to $1.66 \mu \mathrm{g} \mathrm{mL}^{-1}$, respectively) coagulation assays. Both results show that the extract presents a negligible anticoagulant activity. 
A

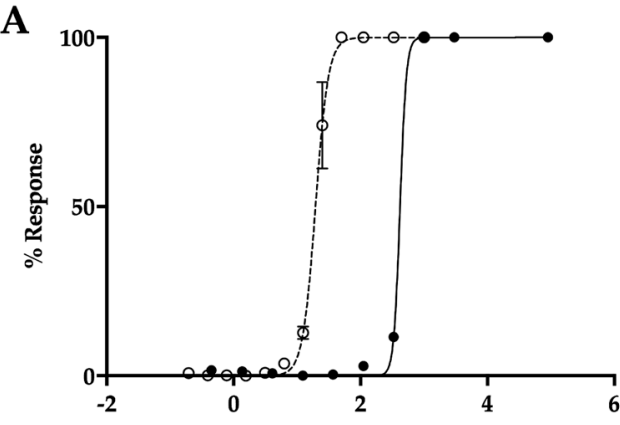

$\log _{10}\left[G A G\left(\mu \mathrm{g} \cdot \mathrm{mL}^{-1}\right)\right]$
B

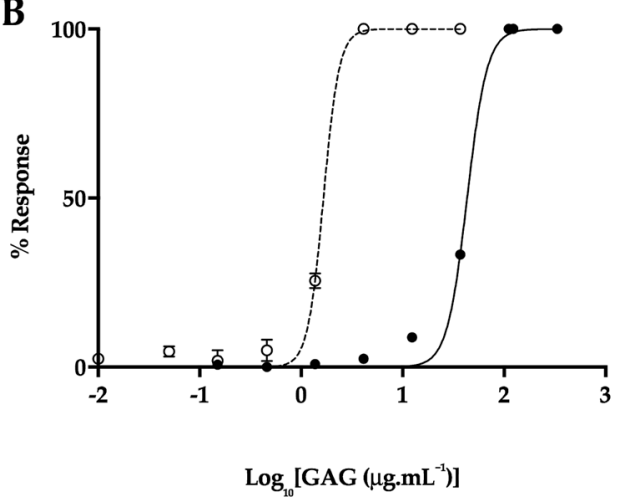

Figure 10. (A) Prothrombin time (PT) and (B) activated partial thromboplastin time (aPTT) inhibitory response $(\bar{x} \%, \pm \mathrm{SD}, \mathrm{n}=3)$ for Hp (open circle, dashed line) and P. pelagicus F5 (closed circle, solid line); PT: Hp EC $\mathrm{EC}_{50}=19.53 \mu \mathrm{g} \mathrm{mL}{ }^{-1}$; P. pelagicus F5, EC $50=420.2 \mu \mathrm{g} \mathrm{mL}^{-1}$. aPTT: $\mathrm{Hp} \mathrm{EC}_{50}=1.66 \mu \mathrm{g} \mathrm{mL}^{-1}$; P. pelagicus $\mathrm{F} 5, \mathrm{EC}_{50}=43.21 \mu \mathrm{g} \mathrm{\textrm {mL } ^ { - 1 }}$.

\section{Discussion}

The glycosaminoglycan extract isolated from P. pelagicus was observed to possess similar electrophoretic behaviour to mammalian HS and Hp, with no bands identified corresponding to CS or DS standards. In contrast, the FTIR and HSQC analyses of P. pelagicus F5 identified regions corresponding to both HS and CS saccharides within the extract. PCA analysis of the FTIR spectra revealed P. pelagicus F5 contained features associated with both HS/Hp and CS/DS, which are typical of crude heparin preparations [41]. This was confirmed by HSQC NMR, which identified N-acetyl peaks associated with both galactosamine (CS) and glucosamine (HS). The absence of an IdoA signal from the NMR spectra suggests that P. pelagicus F5 resembles HS and CS more closely than DS/Hep [55,56]. Peaks corresponding to Gal-6S and 6-OH were identified by NMR analysis, with no detectable 4-O-sulphation, indicating that the CS component of P. pelagicus F5 resembles CSC saccharides. The HS component possesses $>70 \% \mathrm{~N}$-sulphated moieties, which is greater than mammalian HSs published previously, but is not as heavily N-sulphated as mammalian heparins. An intermediate proportion of trisulphated $\Delta$-disaccharides were also identified post-bacterial lyase digestion in P. pelagicus F5 when compared to mammalian HS and Hp samples. Furthermore, the P. pelagicus F5 extract contained a low proportion of $\Delta$-UA-GlcNAc/ $\Delta$-UA-GlcNS, which is typical of more heparin-like structures. This suggests that the HS/Hp component of P. pelagicus F5 consists of a hybrid structure lacking the domain structure of HS and the highly-sulphated regions of $\mathrm{Hp}$.

The absence of a band migrating in a similar manner to that of CS when P. pelagicus F5 was subjected to agarose gel electrophoresis suggests that the polysaccharide is not a mixture of HS and CS chains. The simplicity of the signals in the HSQC spectrum suggests either two separate populations or two distinct domains, while the former is not consistent with the agarose gel electropherogram mentioned previously. The PCA of the FTIR spectra is also in agreement with the presence of discrete, rather than mixed, HS/CS sequences. The precise nature of the arrangement of these stretches remains unknown, although it is well documented that marine-derived GAGs harbour significant and unusual structural features, when compared to those present within their mammalian counterparts [33,43,57-66]. Studies to resolve this technically demanding question are currently in progress.

The P. pelagicus F5 extract was found to possess significant inhibitory potential against human $\mathrm{BACE} 1$, in a manner akin to that of mammalian $\mathrm{Hp}$, as demonstrated by comparable $\mathrm{IC}_{50}$ concentrations determined via FRET. The ability of P. pelagicus F5 to promote BACE1 bioactivity at lower concentrations, owing to the presence of the BACE1 pro-domain [46,47], appears to be at a diminished level compared to mammalian $\mathrm{Hp}$, suggesting differences between these GAGs and the nature of their interactions with human BACE1. This was exemplified when the secondary structural changes in BACE1 (evident from $\mathrm{CD}$ ) in the presence of Hp or P. pelagicus F5 were examined. 
BACE1 has previously been observed to adopt a unique secondary structure at $\mathrm{pH} 4.0$, where catalytic activity is increased, resulting in a predicted increase in beta-sheet and a reduction in alpha-helical structures [50]. When the changes in the secondary structure (evident from CD) of BACE1 in the presence of high concentrations of $\mathrm{Hp}$ (BACE1:Hp ratio of 1:2) was examined, a shift towards the structural features observed for BACE1 alone at $\mathrm{pH} 7.4$ was observed (increase in alpha-helical and reduction in beta sheet structures). At high concentrations (B:F5 ratio of 1:2), the P. pelagicus F5 extract induced similar, but not identical, changes to the secondary structure of human BACE1, when compared to those of $\mathrm{Hp}$ at the same ratio.

In contrast, the CD spectra observed for B:Hp complexes under conditions that facilitate BACE1 promotion (i.e., low $\mathrm{Hp}$ concentrations) demonstrated evidence of an interaction that involves the aromatic amino acids (near UV CD). Tyr-71 is located within the BACE1 flap that has previously been identified to change conformation between the flap-open and flap-closed states [67]. Unfortunately, due to the location of the aromatic residues on the surface of the protein, it is not possible to conclude definitely whether interaction(s) of Hp-based inhibitors with human BACE1 occur at, or near to, the active site. This interpretation is consistent with the previous reports that a conformational change in BACE1 may occur upon heparin binding, which would be required to allow access into the active site [46]. In addition, the increase in BACE1 activity by heparin has been shown to be followed by BACE1 inhibition [47], which may suggest this arrangement is required to allow access to the active site. The results also support the work by Scholefield et al. [18] who showed that the mode of Hp inhibition is non-competitive, and can prevent access of the substrate.

At lower GAG concentrations, differences in BACE1 secondary structure were observed between the B:Hp and B:F5 complexes in the CD spectra, although a similar change in the near UV CD spectra of BACE1 was observed with increased amounts of P. pelagicus F5. This may be accounted for by the reduced potency of $P$. pelagicus F5 with regard to activating BACE1, or indicative of an alternative interaction. The conformational change induced in the near-UV CD spectra of BACE1 is solely the result of the HS/Hp-like component of the P. pelagicus F5 extract. CS has previously been shown to possess diminished BACE1 promotion activity compared to Hp/HS [46].

From a mechanistic standpoint, the decrease in the $\mathrm{T}_{\mathrm{m}} \mathrm{s}$ observed using DSF for both the human BACE1 protein in the presence of either Hp or the P. pelagicus F5 extract, when compared to human BACE1 alone, suggests that the mode of BACE1 inhibition by this class of carbohydrates could both involve structural destabilisation. The Hp-induced thermal instability of human BACE1 occurs in a concentration dependent manner, akin to that of the inhibitory potential of $\mathrm{Hp}$ in the FRET-based bioactivity assay. As for the FRET-based, BACE1 inhibition assays, P. pelagicus [F5] also induces comparable destabilisation of BACE1 with similar $\mathrm{T}_{\mathrm{m}}$ values. A graph of BACE1:GAG $\mathrm{T}_{\mathrm{m}} \mathrm{vs}$. concentration demonstrates similar profiles for the P. pelagicus GAG extract and that of mammalian Hp. The relationship between Hp and P. pelagicus F5 concentration and biological properties that coexists for both FRET-based, BACE1 inhibition and DSF is not mirrored at defined concentrations of $\mathrm{Hp}$ and P. pelagicus F5 with regard to their distinct CD spectra and predicted secondary structure. This would suggest that complex and distinct modes of interactions are present.

One of the major obstacles that precludes the use of mammalian Hp compounds as potential BACE1 inhibitors and pharmaceutical candidates in general is that of the significant anticoagulant potential residual within the biomolecule. This anticoagulant potential is afforded by the propensity of Hp to interact with antithrombin and thereby inhibit the human coagulation pathway, which unperturbed, ultimately results in fibrin clot formation. The anticoagulant potential of P. pelagicus F5 has been shown to be highly attenuated in contrast to mammalian Hp, as measured by both the aPTT and PT clotting assays. These coagulation assays are routinely employed, in clinical settings, to screen for the common pathway in combination with either the intrinsic (aPTT) or extrinsic pathways (PT). 


\section{Materials and Methods}

\subsection{Extraction of Glycosaminoglycans from Portunus pelagicus}

A total of $2.4 \mathrm{~kg}$ Portunus pelagicus tissue (Yeuh Chyang Canned Food Co., Ltd., Nhut Chanh, Vietnam) was homogenised with excess acetone (VWR, UK) and agitated for $24 \mathrm{~h}$ at r.t. Defatted P. pelagicus tissue was recovered via centrifugation, $5670 \mathrm{rcf}$ at r.t. for $10 \mathrm{~min}$, and allowed to air dry. The tissue was then subjected to extensive proteolytic digestion (Alcalase ${ }^{\circledR}$; Novozymes, Bagsværd, Denmark) using $16.8 \mathrm{U} \mathrm{kg}^{-1}$ dried tissue mass, in PBS (w/v; Gibco, Loughborough, UK) made up to a final concentration of $1 \mathrm{M} \mathrm{NaCl}$ (Fisher Scientific, UK), $\mathrm{pH} 8.0$, and incubated at $60^{\circ} \mathrm{C}$ for $24 \mathrm{~h}$. Post-digestion, the supernatant was collected via centrifugation (5670 $\times \mathrm{g}$ for $10 \mathrm{~min}$, r.t.), and subjected to ion exchange chromatography employing Amberlite IRA-900 resin (Sigma-Aldrich, Dorset, UK; hydroxide counterion form) for $24 \mathrm{~h}$ under constant agitation at r.t. Ion exchange resin was recovered by filtration and washed successively with distilled $\mathrm{H}_{2} \mathrm{O}$ (Fisher Scientific, Loughborough, $\mathrm{UK})$ at $60^{\circ} \mathrm{C}$ with two volumes of water and 10 volumes of $1 \mathrm{M} \mathrm{NaCl}$ at r.t. The ion exchange resin was then re-suspended in $1 \mathrm{~L} 3 \mathrm{M} \mathrm{NaCl}$ and agitated for $24 \mathrm{~h}$ at r.t. The ion exchange resin was removed and the filtrate was added to ice cold methanol (VWR, Lutterworth, UK), 1:1 (v/v), prior to incubation for $48 \mathrm{~h}$ at $4{ }^{\circ} \mathrm{C}$. The precipitate formed was recovered by centrifugation at $4{ }^{\circ} \mathrm{C}, 15,400 \times g$ for $1 \mathrm{~h}$ and re-suspended in distilled $\mathrm{H}_{2} \mathrm{O}$. The crude P. pelagicus extract was dialysed against distilled $\mathrm{H}_{2} \mathrm{O}$ (3.5 kDa MWCO membrane; Biodesign, Carmel, NY, USA) for $48 \mathrm{~h}$ prior to syringe filtration $(0.2 \mu \mathrm{m})$ and lyophilisation. The crude GAG extract was re-suspended in $1 \mathrm{~mL}$ HPLC-grade $\mathrm{H}_{2} \mathrm{O}$ and loaded onto a pre-packed DEAE-Sephacel column (10 mm I.D. $\times 10 \mathrm{~cm}$; GE Healthcare, Buckinghamshire, UK) at a flow rate of $1 \mathrm{~mL} \mathrm{~min}^{-1}$. The column was eluted using a stepwise $\mathrm{NaCl}$ gradient of $0,0.25,0.5,0.8$, 1 and $2 \mathrm{M} \mathrm{NaCl}$ at a flow rate of $1 \mathrm{~mL} \mathrm{~min}^{-1}$, with elution monitored in-line at $\lambda_{\mathrm{abs}}=232 \mathrm{~nm}$ (using a UV/Vis, binary gradient HPLC system; Cecil Instruments, Cambridge, UK), resulting in six fractions (F1-F6, respectively). Each of the eluted fractions was dialysed against distilled $\mathrm{H}_{2} \mathrm{O}$, employing a 3.5-kDa MWCO (Biodesign, Carmel, NY, USA) for $48 \mathrm{~h}$ under constant agitation. The retentate obtained for $\mathrm{F} 5$ was lyophilised and stored at $4{ }^{\circ} \mathrm{C}$ prior to use.

\subsection{Agarose Gel Electrophoresis}

Agarose gel electrophoresis was performed in $0.55 \%(w / v)$ agarose gels $(8 \times 8 \mathrm{~cm}, 1.5 \mathrm{~mm}$ thick $)$ prepared in 1,3-diaminopropane-acetate buffer at $\mathrm{pH} 9.0$ (VWR, Lutterworth, UK), $2-7.5 \mu \mathrm{g}$ P. pelagicus F5 or GAG standards were subjected to electrophoresis utilizing a X-Cell SureLock ${ }^{\mathrm{TM}}$ Mini-Cell Electrophoresis System (ThermoFisher, Altrincham, UK). Electrophoresis was performed in $0.5 \mathrm{M}$ 1,3-diaminopropane-acetate buffer ( $\mathrm{pH} 9.0$ ), at a constant voltage of $150 \mathrm{~V}(\sim 100 \mathrm{~mA}$ ) for $\sim 30 \mathrm{~min}$ or until the dye front had migrated $\sim 8 \mathrm{~cm}$ from the origin. The gels were then precipitated with $0.1 \%$ $w / v$ cetyltrimethylammonium bromide solution (VWR, Lutterworth, UK) for a minimum of $4 \mathrm{~h}$ and then stained for $1 \mathrm{~h}$ in $0.1 \%$ toluidine blue dissolved in acetic acid:ethanol:water (0.1:5:5). Gels were de-stained in acetic acid:ethanol:water $(0.1: 5: 5 v / v)$ for $\sim 30 \mathrm{~min}$ prior to image acquisition with GIMP software (v2.8, Berkeley, CA, USA) and processing with ImageJ (v1.51(100), Madison, WI, USA).

\subsection{Attenuated FTIR Spectral Analysis of Marine-Derived Glycosaminoglycans}

Samples (10 mg, lyophilised) were recorded using a Bruker Alpha I spectrometer in the region of 4000 to $400 \mathrm{~cm}^{-1}$ for 32 scans at a resolution of $2 \mathrm{~cm}^{-1}$ (approx 70 seconds acquisition time), 5 times. Spectral acquisition was carried out using OPUS software (v8.1, Bruker, Coventry, UK) with correction to remove the residual spectrum of the sampling environment.

Spectral processing and subsequent data analyses were performed using an Asus Vivobook Pro (M580VD-EB76, Taipei, Taiwan) equipped with an intel core i7-7700HQ. Spectra were smoothed, employing a Savitzky-Golay smoothing algorithm (R studio v1.1.463; signal package, sgolayfilter), to a 2nd-degree polynomial with 21 neighbours prior to baseline correction employing a 7th-order polynomial and subsequent normalisation (0-1). $\mathrm{CO}_{2}$ and $\mathrm{H}_{2} \mathrm{O}$ regions were removed prior to 
further analysis in order to negate environmental variability $\left(<700 \mathrm{~cm}^{-1}\right.$, between 2000 and 2500 $\mathrm{cm}^{-1}$ and $>3600 \mathrm{~cm}^{-1}$ ). Second derivatives plots were calculated using the Savitzky-Golay algorithm, with 41 neighbours and a 2nd-order polynomial.

The normalised and corrected matrix of intensities was subject to PCA using singular value decomposition in R studio (v1.1.463, Boston, MA, USA) with the mean-centred, base prcomp function deployed.

\subsection{Nuclear Magnetic Resonance (NMR)}

NMR experiments were performed upon P. pelagicus F5 (5 mg) dissolved in $\mathrm{D}_{2} \mathrm{O}(600 \mu \mathrm{L}$; VWR, São Paulo, Brazil) containing TMSP $(0.003 \%$ v/v; VWR, Brazil) at $343 \mathrm{~K}$ using a 500-MHz Avance Neo spectrometer fitted with a 5-mm TXI Probe (Bruker, São Paulo, Brazil)). In addition to 1-dimensional $\left({ }^{1} \mathrm{H}\right)$ spectra, ${ }^{1} \mathrm{H}-{ }^{13} \mathrm{C}$ Heteronuclear Single-Quantum Correlation (HSQC) 2-dimensional spectra were collected using standard pulse sequences available. Spectra were processed and integrated using TopSpin (Bruker, São Paulo, Brazil)

\subsection{Constituent $\Delta$-Disaccharide Analysis of Hp/HS-Like, Marine-Derived Carbohydrates}

Pharmaceutical (API) grade, porcine intestinal mucosal heparin (193 IU mg ${ }^{-1}$; Celsus, Cincinnati, $\mathrm{OH}, \mathrm{USA}$ ) and P. pelagicus F5 carbohydrate samples were re-suspended in lyase digestion buffer (50 $\mu \mathrm{L}$; $25 \mathrm{mM}$ sodium acetate, $5 \mathrm{mM}$ calcium acetate (VWR, Lutterworth, UK), $\mathrm{pH}$ 7) prior to exhaustive digestion by the sequential addition of a cocktail of the three recombinantly expressed heparinase enzymes (I, III and II) from the soil bacterium Flavobacterium heparinum ( $2.5 \mathrm{mIU} \mathrm{mg}^{-1}$; Iduron, Alderley Edge, UK). Samples were incubated for $4 \mathrm{~h}$ at $37^{\circ} \mathrm{C}$ prior to a further addition of the same quantity of enzymes and an additional overnight incubation. Samples were then heated briefly at $95^{\circ} \mathrm{C}$ post-enzyme digestion (5 $\mathrm{min}$ ) and allowed to cool.

Denatured heparinase enzymes were removed from the sample solution by immobilisation upon a pre-washed (50\% methanol (aq.) followed by HPLC-grade $\mathrm{H}_{2} \mathrm{O}$ ) $\mathrm{C}^{18}$ spin column (Pierce, Altrincham, $\mathrm{UK})$, whereby the newly liberated $\Delta$-disaccharides were present in the column eluate upon washing with HPLC-grade $\mathrm{H}_{2} \mathrm{O}$.

Lyophilised $\Delta$-disaccharide samples from $\mathrm{Hp}$ and P. pelagicus F5 were desalinated by immobilisation up on graphite spin columns (Pierce, Altrincham, UK) that had been extensively prewashed with $80 \%$ acetonitrile, $0.5 \%$ (aq.) trifluoroacetic acid and HPLC-grade $\mathrm{H}_{2} \mathrm{O}$ prior to use. $\Delta$-disaccharides liberated from the exhaustive, heparinase digestion were separated from buffer salts by extensive washing with HPLC-grade $\mathrm{H}_{2} \mathrm{O}$ prior to elution with a solution of $40 \%$ acetonitrile, $0.5 \%$ trifluoroacetic acid (aq.). Contaminant, non $\Delta$-disaccharide components of the spin column eluate were removed by serial lyophilization prior to chromatographic separation, using high performance anion exchange chromatography (HPAEC).

Heparinase digested samples $(50 \mu \mathrm{g})$ were made up in HPLC-grade $\mathrm{H}_{2} \mathrm{O}(1 \mathrm{~mL})$ immediately before injection onto a ProPac PA-1 analytical column $(4 \times 250 \mathrm{~mm}$, ThermoFisher Scientific, Altrincham, $\mathrm{UK}$ ), and pre-equilibrated in HPLC-grade $\mathrm{H}_{2} \mathrm{O}$ at a flow rate of $1 \mathrm{~mL} \mathrm{~min}^{-1}$. The column was held under isocratic flow for 10 min prior to developing a linear gradient from 0 to $2 \mathrm{M} \mathrm{NaCl}$ (HPLC grade; VWR, UK) over $60 \mathrm{~min}$. Eluted $\Delta$-disaccharides were detected absorbing within the UV range $\lambda_{\text {abs }}$ $=232 \mathrm{~nm}$ via the unsaturated $\mathrm{C}=\mathrm{C}$ bond, present between $\mathrm{C}_{4}$ and $\mathrm{C}_{5}$ of the uronic acid residues, introduced as a consequence of lyase digestion.

Authentic $\Delta$-disaccharide reference standards, comprising the 8 common standards found in $\mathrm{Hp}$ and HS (Iduron, Alderley Edge, UK), were employed as a mixture (each at $5 \mu \mathrm{g} \mathrm{mL}^{-1}$ ) and served as chromatographic references with elution times cross-correlated with $\mathrm{Hp}$ and P. pelagicus $\mathrm{F} 5$ samples. The column was washed extensively with $2 \mathrm{M} \mathrm{NaCl}$ and $\mathrm{HPLC}$-grade $\mathrm{H}_{2} \mathrm{O}$ prior to use and between runs. 


\subsection{Determination of Human BACE1 Inhibitory Activity Using Förster Resonance Energy Transfer}

P. pelagicus F5 and Hp were assayed for inhibitory potential against human $\beta$-secretase, tag free (BACE1; ACRO Biosystems, Cambridge, MA, USA), using the fluorescence resonance energy transfer (FRET) inhibition assay, essentially as described by Patey et al. (2006) [19]. Human BACE1 (312.5 ng), and P. pelagicus $\mathrm{F} 5$ or $\mathrm{Hp}$ were incubated in $50 \mathrm{mM}$ sodium acetate at $\mathrm{pH} 4.0$ at $37^{\circ} \mathrm{C}$ for $10 \mathrm{~min}$, followed by the addition a quenched fluorogenic peptide substrate $(6.25 \mu \mathrm{M}$; Biomatik, Cambridge, Ontario, Canada; MCA-SEVNLDAEFRK(DNP)RR-NH ${ }_{2}$; pre-incubated at $37^{\circ} \mathrm{C}$ for $10 \mathrm{~min}$ ) to a final well volume of $50 \mu \mathrm{L}$. Fluorescent emission was recorded using a Tecan Infinite ${ }^{\circledR}$ M200 Pro multi-well plate reader (Tecan Group Ltd., Männedorf, Switzerland) with i-control ${ }^{\mathrm{TM}}$ software $\left(\lambda_{\mathrm{ex}}=320 \mathrm{~nm}\right.$, $\lambda_{\mathrm{em}}=405 \mathrm{~nm}$ ) over $90 \mathrm{~min}$. The relative change in fluorescence per minute was calculated in the linear range of the no inhibitor control, with normalized percentage inhibition calculated $(\% \pm \mathrm{SD}, \mathrm{n}=3)$ compared to the $\bar{x}$ of substrate only and no inhibitor control, followed by fitting to a four-parameter logistics model using Prism 7 (GraphPad Software, San Diego, CA, USA).

\subsection{Secondary Structure Determination of Human BACE1 by Circular Dichroism Spectroscopy}

The circular dichroism (CD) spectra of native, human BACE1 $(6.12 \mu \mathrm{M}, 30 \mu \mathrm{L}$; Acro Biosystems, USA) in $50 \mathrm{mM}$ sodium acetate ( $\mathrm{pH}$ 4.0; VWR, Lutterworth, UK) was obtained using a J-1500 Jasco CD spectrometer and Spectral Manager II software, equipped with a 0.2-mm path length quartz cuvette (Hellma, Plainview, NY, USA) operating at a scan speed of $100 \mathrm{~nm} \mathrm{~min}{ }^{-1}$ with 1-nm resolution over the range $\lambda=190-320 \mathrm{~nm}$. Spectra obtained were the mean of five independent scans. Human BACE1 was buffer exchanged (in order to remove commercially supplied buffer) prior to spectral analysis using a 10-kDa Vivaspin centrifugal filter (Sartorius, Goettingen, Germany) at 12,000 $\mathrm{g}$ washed thrice. Collected data was processed using Spectral Manager II software and data analysis was carried out with GraphPad Prism 7, employing a 2nd-order polynomial smoothed to 9 neighbours. Secondary structure prediction was performed utilizing the BeStSel analysis server on the unsmoothed data [48]. To ensure the CD spectral change of BACE1 in the presence of each GAG was not altered owing to the addition of the GAG alone, which are known to possess CD spectra at high concentrations [68,69] GAG control spectra were subtracted before analysis. In addition, the theoretical, summative CD spectra was confirmed to differ from the observed experimental CD spectra, thereby indicating that the change in the CD spectra compared to that of BACE1 alone is a result of a conformational change upon binding to the GAG. The conformational change observed is believed to occur as a result of changes solely in BACE1 secondary structure, as GAG controls exhibited negligible spectra at the concentration used. All CD data has been presented with GAG controls subtracted.

\subsection{Investigating the Thermal Stability of Human BACE1 with Differential Scanning Fluorimetry}

Differential scanning fluorimetry (DSF) was carried out using the method of Uniewicz et al. (2010) [70] based on a modification to the original method of Niesen et al. (2007) [71]. DSF was performed on human BACE1 $(1 \mu \mathrm{g})$ using 96-well qPCR plates (AB Biosystems, Warrington, UK) with 20X Sypro Orange (Invitrogen, Warrington, UK) in $50 \mathrm{mM}$ sodium acetate, $\mathrm{pH}$ 4.0, in a final well volume of $40 \mu \mathrm{l}$. Hp or mGAG were included, as necessary, to a maximal concentration of $200 \mu \mathrm{g} \mathrm{mL} \mathrm{L}^{-1}$. An AB Biosystems StepOne plus qPCR machine, with the TAMRA filter set deployed, was used to carry out melt curve experiments, with an initial incubation phase of 2 min at $20^{\circ} \mathrm{C}$ increasing by $0.5^{\circ} \mathrm{C}$ increments every $30 \mathrm{~s}$ up to a final temperature of $90^{\circ} \mathrm{C}$. Data analysis was completed using Prism 7 (GraphPad Software, San Diego, CA, USA) with the first derivative plots smoothed to 19 neighbours, using a 2nd-order polynomial (Savitzky-Golay). The peak of the first derivatives (yielding $\mathrm{T}_{\mathrm{m}} \mathrm{s}$ ) was determined using MatLab software (R20018a, MathWorks, Cambridge, UK). 


\subsection{Activated Partial Thromboplastin Time (aPTT)}

Serially diluted GAG samples $(25 \mu \mathrm{L})$ were incubated with pooled, normal human citrated plasma $(50 \mu \mathrm{L}$; Technoclone, Surrey, UK) and Pathromtin SL reagent (50 $\mu \mathrm{L}$; Siemens, Erlangen, Germany) for 2 mins at $37^{\circ} \mathrm{C}$ prior to the addition of calcium chloride ( $25 \mu \mathrm{L}, 50 \mathrm{mM}$; Alfa Aesar, Heysham, UK). The time taken for clot formations to occur (an upper maximal of 2 mins was imposed, represented as $100 \%$ inhibition of clotting) was recorded using a Thrombotrak Solo coagulometer (Axis-Shield). HPLC-grade $\mathrm{H}_{2} \mathrm{O}(0 \%$ inhibition of clotting, representing a normal aPTT clotting time, of $\approx 37-40$ seconds) and porcine mucosal heparin (193 IU mg ${ }^{-1}$; Celsus, Cincinnati, OH, USA) were screened as controls. The $\mathrm{EC}_{50}$ values of all test and control samples were determined using a sigmoidal dose response curve fitted with Prism 7 (GraphPad Software, San Diego, CA, USA).

\subsection{Prothrombin Time (PT)}

Serially diluted GAGs $(50 \mu \mathrm{L})$ or control $\left(\mathrm{H}_{2} \mathrm{O}, \mathrm{HPLC}\right.$ grade) were incubated with pooled, normal human citrated plasma $(50 \mu \mathrm{L})$ for 1 minute at $37^{\circ} \mathrm{C}$ prior to the addition of Thromborel $\mathrm{S}$ reagent ( $50 \mu \mathrm{L}$; Siemens, Erlangen, Germany). The time taken for clot formations to occur (an upper maximal of 2 min was imposed, representing 100\% inhibition of clotting) was recorded using a Thrombotrak Solo coagulometer. HPLC-grade $\mathrm{H}_{2} \mathrm{O}(0 \%$ inhibition of clotting, representing a normal PT clotting time of $\approx 13-14 \mathrm{~s}$ ) and porcine mucosal heparin (193 IU mg ${ }^{-1}$; Celsus, Cincinnati, OH, USA) were screened as controls. The $\mathrm{EC}_{50}$ values of all test and control samples were determined using a sigmoidal dose response curve fitted with Prism 7 (GraphPad Software, San Diego, CA, USA).

\section{Conclusions}

While the search for effective AD treatments is still on-going, GAGs offer a route to BACE1 inhibition that surmounts the challenge presented by the large substrate-binding cleft of the enzyme and the unfavourable pharmokinetics of peptide-based inhibitors. Heparin, a GAG from mammalian sources (usually porcine or bovine intestinal tissue), has long been known to possess potent BACE1 inhibitory activity [18-20] but also exhibits undesirable anticoagulant properties. The P. pelagicus GAG of the present study largely circumvents the anticoagulant limitations of mammalian heparins while maintaining comparable, low $\mathrm{IC}_{50}$ BACE1 inhibition values. Additional advantages with marine-derived GAGs is that they offer sources, derived from waste material of otherwise very low economic value, that are free from contamination with mammalian pathogens (e.g., BSE) and avoid many of the religious and social issues associated with mammalian products [72]. Interestingly, the mechanism by which the present product from P. pelagicus inhibits BACE1 is complex, concentration dependent and appears to be distinct from that of mammalian heparin, suggesting marine GAGs as a potential starting point for future drug development. Furthermore, as heparin has been shown to positively modulate distinct pathophysiological processes associated with AD [23], this class of molecules may hold the potential for the delivery of a multi-target AD therapeutic. The present contribution highlights the potential offered by the largely unexplored chemical space defined by marine-derived GAGs.

Supplementary Materials: The following are available online at http://www.mdpi.com/1660-3397/17/5/293/s1, Figure S1: The CD structural change of BACE1 observed in the presence of P. pelagicus F5 with a ratio of 2:1 w/w.

Author Contributions: M.S., C.M.-W., L.C., S.G. and E.Y. designed and conceived the project. C.M.-W. performed all experimentation with the technical assistance of L.C., P.P., S.G. and D.F. A.D. performed FTIR and carried out principal component analysis on data sets and M.L. and M.G. performed and analysed the NMR data. M.S., C.M.-W., L.C., S.G. and E.Y. wrote the manuscript and all authors contributed to the final version of the manuscript.

Funding: The authors would like to thank the Engineering and Physical Sciences Research Council, UK (M.S.), the Biotechnology and Biological Sciences Research Council, UK (M.S. and E.Y.), the Medical Research Council, UK (M.S., L.C. and E.Y.), Intellihep Ltd., UK (C.M.-W. and M.S.), MI Engineering Ltd., UK (A.D. and M.S.) and Financiadora de Estudos e Projetos (FINEP) (M.L.) for financial support. 
Acknowledgments: The authors would like to thank Sarah Taylor for technical assistance with the use of CD instrumentation.

Conflicts of Interest: The funders had no role in the study design, data collection and interpretation, or the decision to submit the work for publication.

\section{References}

1. Lane, C.; Hardy, J.; Schott, J.M. Alzheimer's disease. Eur. J. Neurol. 2017, 25, 59-70. [CrossRef]

2. Cruts, M.; Theuns, J.; Van Broeckhoven, C. Locus-specific mutation databases for neurodegenerative brain diseases. Hum. Mutat. 2012, 33, 1340-1344. [CrossRef] [PubMed]

3. Carreiras, M.; Mendes, E.; Perry, M.; Francisco, A.; Marco-Contelles, J. The Multifactorial Nature of Alzheimer's Disease for Developing Potential Therapeutics. Curr. Top. Med. Chem. 2014, 13, 1745-1770. [CrossRef]

4. Ibrahim, M.M.; Gabr, M.T. Multitarget therapeutic strategies for Alzheimer's disease. Neural Regen. Res. 2019, 14, 437-440.

5. Cai, H.; Wang, Y.; McCarthy, D.; Wen, H.; Borchelt, D.R.; Price, D.L.; Wong, P.C. BACE1 is the major $\beta$-secretase for generation of A $\beta$ peptides by neurons. Nat. Neurosci. 2001, 4, 233-234. [CrossRef] [PubMed]

6. Querfurth, H.W.; LaFerla, F.M. Alzheimer's Disease. N. Engl. J. Med. 2010, 362, 329-344. [CrossRef]

7. Lichtenthaler, S.F.; Haass, C.; Steiner, H. Regulated intramembrane proteolysis-Lessons from amyloid precursor protein processing. J. Neurochem. 2011, 117, 779-796. [CrossRef] [PubMed]

8. Walsh, D.M.; Selkoe, D.J. A $\beta$ Oligomers-A decade of discovery. J. Neurochem. 2007, 101, $1172-1184$. [CrossRef]

9. Thinakaran, G.; Koo, E.H. Amyloid precursor protein trafficking, processing, and function. J. Biol. Chem. 2008, 283, 29615-29619. [CrossRef] [PubMed]

10. Vassar, R. BACE1 inhibition as a therapeutic strategy for Alzheimer's disease. J. Sport Health Sci. 2016, 5, 388-390. [CrossRef] [PubMed]

11. Roberds, S.L.; Anderson, J.; Basi, G.; Bienkowski, M.J.; Branstetter, D.G.; Chen, K.S.; Freedman, S.B.; Frigon, N.L.; Games, D.; Hu, K.; et al. BACE knockout mice are healthy despite lacking the primary beta-secretase activity in brain: Implications for Alzheimer's disease therapeutics. Hum. Mol. Genet. 2001, 10, 1317-1324. [CrossRef]

12. Luo, Y.; Bolon, B.; Kahn, S.; Bennett, B.D.; Babu-Khan, S.; Denis, P.; Fan, W.; Kha, H.; Zhang, J.; Gong, Y.; et al. Mice deficient in BACE1, the Alzheimer's $\beta$-secretase, have normal phenotype and abolished $\beta$-amyloid generation. Nat. Neurosci. 2001, 4, 231-232. [CrossRef] [PubMed]

13. Dominguez, D.; Tournoy, J.; Hartmann, D.; Huth, T.; Cryns, K.; Deforce, S.; Serneels, L.; Camacho, I.E.; Marjaux, E.; Craessaerts, K.; et al. Phenotypic and Biochemical Analyses of BACE1- and BACE2-deficient Mice. J. Biol. Chem. 2005, 280, 30797-30806. [CrossRef]

14. Ohno, M.; Sametsky, E.A.; Younkin, L.H.; Oakley, H.; Younkin, S.G.; Citron, M.; Vassar, R.; Disterhoft, J.F. BACE1 deficiency rescues memory deficits and cholinergic dysfunction in a mouse model of Alzheimer's disease. Neuron 2004, 41, 27-33. [CrossRef]

15. Ohno, M.; Cole, S.L.; Yasvoina, M.; Zhao, J.; Citron, M.; Berry, R.; Disterhoft, J.F.; Vassar, R. BACE1 gene deletion prevents neuron loss and memory deficits in 5XFAD APP/PS1 transgenic mice. Neurobiol. Dis. 2007, 26, 134-145. [CrossRef] [PubMed]

16. McConlogue, L.; Buttini, M.; Anderson, J.P.; Brigham, E.F.; Chen, K.S.; Freedman, S.B.; Games, D.; Johnson-Wood, K.; Lee, M.; Zeller, M.; et al. Partial Reduction of BACE1 Has Dramatic Effects on Alzheimer Plaque and Synaptic Pathology in APP Transgenic Mice. J. Biol. Chem. 2007, 282, 26326-26334. [CrossRef] [PubMed]

17. Vassar, R. BACE1 inhibitor drugs in clinical trials for Alzheimer's disease. Alzheimer's Res. Ther. 2014, 6, 89. [CrossRef] [PubMed]

18. Scholefield, Z.; Yates, E.A.; Wayne, G.; Amour, A.; McDowell, W.; Turnbull, J.E. Heparan sulfate regulates amyloid precursor protein processing by BACE1, the Alzheimer's beta-secretase. J. Cell Biol. 2003, 163, 97-107. [CrossRef] [PubMed] 
19. Patey, S.J.; Edwards, E.A.; Yates, E.A.; Turnbull, J.E. Heparin derivatives as inhibitors of BACE-1, the Alzheimer's $\beta$-secretase, with reduced activity against factor Xa and other proteases. J. Med. Chem. 2006, 49, 6129-6132. [CrossRef]

20. Patey, S.J.; Edwards, E.A.; Yates, E.A.; Turnbull, J.E. Engineered heparins: Novel beta-secretase inhibitors as potential Alzheimer's disease therapeutics. Neurodegener. Dis. 2008, 5, 197-199. [CrossRef]

21. Bergamaschini, L.; Rossi, E.; Storini, C.; Pizzimenti, S.; Distaso, M.; Perego, C.; De Luigi, A.; Vergani, C.; De Simoni, M.G. Peripheral Treatment with Enoxaparin, a Low Molecular Weight Heparin, Reduces Plaques and $\beta$-Amyloid Accumulation in a Mouse Model of Alzheimer's Disease. J. Neurosci. 2004, 24, 4181-4186. [CrossRef]

22. Timmer, N.M.; van Dijk, L.; van der Zee, C.E.; Kiliaan, A.; de Waal, R.M.; Verbeek, M.M. Enoxaparin treatment administered at both early and late stages of amyloid $\beta$ deposition improves cognition of APPswe/PS1dE9 mice with differential effects on brain A $\beta$ levels. Neurobiol. Dis. 2010, 40, 340-347. [CrossRef] [PubMed]

23. Bergamaschini, L.; Rossi, E.; Vergani, C.; De Simoni, M.G. Alzheimer's disease: Another target for heparin therapy. Sci. World J. 2009, 9, 891-908. [CrossRef]

24. Leveugle, B.; Ding, W.; Laurence, F.; Dehouck, M.P.; Scanameo, A.; Cecchelli, R.; Fillit, H. Heparin oligosaccharides that pass the blood-brain barrier inhibit beta-amyloid precursor protein secretion and heparin binding to beta-amyloid peptide. J. Neurochem. 1998, 70, 736-744. [CrossRef] [PubMed]

25. Hoffart, V.; Lamprecht, A.; Maincent, P.; Lecompte, T.; Vigneron, C.; Ubrich, N. Oral bioavailability of a low molecular weight heparin using a polymeric delivery system. J. Control. Release 2006, 113, 38-42. [CrossRef]

26. Stewart, K.L.; Hughes, E.; Yates, E.A.; Middleton, D.A.; Radford, S.E. Molecular Origins of the Compatibility between Glycosaminoglycans and A 340 Amyloid Fibrils. J. Mol. Biol. 2017, 429, 2449-2462. [CrossRef] [PubMed]

27. Mycroft-West, C.J.; Yates, E.A.; Skidmore, M.A. Marine glycosaminoglycan-like carbohydrates as potential drug candidates for infectious disease. Biochem. Soc. Trans. 2018, 46, 919-929. [CrossRef] [PubMed]

28. Valcarcel, J.; Nova-Carballal, R.; Perez-Martin, I.R.; Reis, L.R.; Vazeuez, A.J. Glycosaminoglycans from Marine Sources as therapeutic Agents. Biotechnol. Adv. 2017, 35, 711-725. [CrossRef]

29. Bergefall, K.; Trybala, E.; Johansson, M.; Uyama, T.; Yamada, S.; Kitagawa, H.; Sugahara, K.; Bergstrom, T. Chondroitin sulfate characterized by the E-disaccharide unit is a poten inhibtor of herpes simplex virus infectivity and provides the virus binding sites on gro2C cells. J. Biol. Chem. 2005, 280, 32193-32199. [CrossRef]

30. Huang, N.; Wu, M.Y.; Zheng, C.B.; Zhu, L.; Zhao, J.H.; Zheng, Y.T. The depolymerized fucosylated chondroitin sulfate from sea cucumber potently inhibits HIV replication via interfering with virus entry. Carbohydr. Res. 2013, 380, 64-69. [CrossRef]

31. Bastos, F.M.; Albrecht, L.; Kozlowski, O.E.; Lopes, P.C.S.; Blanco, C.Y.; Carlos, C.B.; Castineiras, C.; Vicente, P.C.; Werneck, C.C.; Gerhard, W.; et al. Fucosylated Chondroitin Sulphate Inhibits Plasmodium falciparum Cytoadhesion and Merozoite Invasion. Antimicrob. Agents Chemother. 2014, 58, 1862-1871. [CrossRef] [PubMed]

32. Marques, J.; Vilanova, E.; Mourao, S.A.P.; Fernandez-Busquets, X. Marine organism sulfated polysaccharides exhibiting significant antimalarial activity and inhibition of red blood cell invasion by plasmodium. Sci. Rep. 2016, 6, 24368. [CrossRef]

33. Brito, A.S.; Arimatéia, D.S.; Souza, L.R.; Lima, M.A.; Santos, V.O.; Medeiros, V.P.; Ferreira, P.A.; Silva, R.A.; Ferreira, C.V.; Justo, G.Z.; et al. Anti-inflammatory properties of a heparin-like glycosaminoglycan with reduced anti-coagulant activity isolated from a marine shrimp. Bioorg. Med. Chem. 2008, 16, 9588-9595. [CrossRef]

34. Suleria, H.A.R.; Masci, P.P.; Addepalli, R.; Chen, W.; Gobe, G.C.; Osborne, S.A. In vitro anti-thrombotic and anti-coagulant properties of blacklip abalone (Haliotis rubra) viscera hydrolysate. Anal. Bioanal. Chem. 2017, 409, 4195-4205. [CrossRef]

35. Gomes, A.M.; Kozlowski, E.O.; Borsig, L.; Teixeira, F.C.; Vlodavsky, I.; Pavão, M.S.G. Antitumor properties of a new non-anticoagulant heparin analog from the mollusk Nodipecten nodosus: Effect on P-selectin, heparanase, metastasis and cellular recruitment. Glycobiology 2015, 25, 386-393. [CrossRef] [PubMed]

36. Khurshid, C.; Pye, D.; Khurshid, C.; Pye, D.A. Isolation and Composition Analysis of Bioactive Glycosaminoglycans from Whelk. Mar. Drugs 2018, 16, 171. [CrossRef] [PubMed] 
37. Aldairi, A.F.; Ogundipe, O.D.; Pye, D.A.; Aldairi, A.F.; Ogundipe, O.D.; Pye, D.A. Antiproliferative Activity of Glycosaminoglycan-Like Polysaccharides Derived from Marine Molluscs. Mar. Drugs 2018, 16, 63. [CrossRef]

38. Hu, S.; Jiang, W.; Li, S.; Song, W.; Ji, L.; Cai, L.; Liu, X. Fucosylated chondroitin sulphate from sea cucumber reduces hepatic endoplasmic reticulum stress-associated inflammation in obesity mice. J. Funct. Foods 2015, 16, 352-363. [CrossRef]

39. Gomes, A.M.; Kozlowski, E.O.; Pomin, V.H.; de Barros, C.M.; Zaganeli, J.L.; Pavão, M.S. Unique Extracellular Matrix Heparan Sulfate from the Bivalve Nodipecten nodosus (Linnaeus, 1758) Safely Inhibits Arterial Thrombosis after Photochemically Induced Endothelial Lesion. J. Biol. Chem. 2010, 285, 7312-7323. [CrossRef]

40. Hikino, M.; Mikami, T.; Faissner, A.; Vilela-Silva, A.-C.E.; Pavão, M.S.G.; Sugahara, K. Oversulfated Dermatan Sulfate Exhibits Neurite Outgrowth-promoting Activity toward Embryonic Mouse Hippocampal Neurons. J. Biol. Chem. 2003, 278, 43744-43754. [CrossRef] [PubMed]

41. Devlin, A.; Mycroft-west, C.J.; Guerrini, M.; Yates, E.A. Analysis of solid-state heparin samples by ATR-FTIR spectroscopy. bioRxiv 2019. [CrossRef]

42. Skidmore, M.A.; Guimond, S.E.; Turnbull, J.E.; Dumax-Vorzet, A.F.; Yates, E.A.; Atrih, A. High sensitivity separation and detection of heparan sulfate disaccharides. J. Chromatogr. A 2006, 1135, 52-56. [CrossRef]

43. Andrade, P.V.G.; Lima, A.M.; de Souza Junior, A.A.; Fareed, J.; Hoppensteadt, A.D.; Santos, E.; Chavante, F.S.; Oliveira, W.F.; Rocha, A.O.H.; Nader, B.H. A heparin-like compound isolated from a marine crab rich in glucuronic acid 2-O-sulfate presents low anticoagulant activity. Carbohydr. Polym. 2013, 94, 647-654. [CrossRef] [PubMed]

44. Dietrich, C.P.; Tersariol, I.L.; Toma, L.; Moraes, C.T.; Porcionatto, M.A.; Oliveira, F.W.; Nader, H.B. Structure of heparan sulfate: Identification of variable and constant oligosaccharide domains in eight heparan sulfates of different origins. Cell. Mol. Biol. 1998, 44, 417-429.

45. Zhang, Z.; Xie, J.; Liu, H.; Liu, J.; Linhardt, R.J. Quantification of heparan sulfate disaccharides using ion-pairing reversed-phase microflow high-performance liquid chromatography with electrospray ionization trap mass spectrometry. Anal. Chem. 2009, 81, 4349-4355. [CrossRef]

46. Klaver, D.W.; Wilce, M.C.J.; Gasperini, R.; Freeman, C.; Juliano, J.P.; Parish, C.; Foa, L.; Aguilar, M.-I.; Small, D.H. Glycosaminoglycan-induced activation of the $\beta$-secretase (BACE1) of Alzheimer's disease. J. Neurochem. 2010, 112, 1552-1561. [CrossRef]

47. Beckman, M.; Holsinger, R.M.D.; Small, D.H. Heparin activates $\beta$-secretase (BACE1) of Alzheimer's disease and increases autocatalysis of the enzyme. Biochemistry 2006, 45, 6703-6714. [CrossRef] [PubMed]

48. Micsonai, A.; Wien, F.; Kernya, L.; Lee, Y.-H.; Goto, Y.; Réfrégiers, M.; Kardos, J. Accurate secondary structure prediction and fold recognition for circular dichroism spectroscopy. Proc. Natl. Acad. Sci. USA 2015, 112, E3095-E3103. [CrossRef] [PubMed]

49. Gasymov, O.K.; Abduragimov, A.R.; Glasgow, B.J. Probing tertiary structure of proteins using single Trp mutations with circular dichroism at low temperature. J. Phys. Chem. B 2014, 118, 986-995. [CrossRef] [PubMed]

50. De Simone, A.; Mancini, F.; Real Fernàndez, F.; Rovero, P.; Bertucci, C.; Andrisano, V. Surface plasmon resonance, fluorescence, and circular dichroism studies for the characterization of the binding of BACE-1 inhibitors. Anal. Bioanal. Chem. 2013, 405, 827-835. [CrossRef] [PubMed]

51. Greenfield, N.J. Using circular dichroism spectra to estimate protein secondary structure. Nat. Protoc. 2006, 1, 2876. [CrossRef] [PubMed]

52. Shimizu, H.; Tosaki, A.; Kaneko, K.; Hisano, T.; Sakurai, T.; Nukina, N. Crystal Structure of an Active Form of BACE1, an Enzyme Responsible for Amyloid $\beta$ Protein Production. Mol. Cell. Biol. 2008, 28, 3663-3671. [CrossRef]

53. Sreerama, N.; Woody, R.W. On the analysis of membrane protein circular dichroism spectra. Protein Sci. 2004, 13, 100-112. [CrossRef] [PubMed]

54. Lo, M.-C.; Aulabaugh, A.; Jin, G.; Cowling, R.; Bard, J.; Malamas, M.; Ellestad, G. Evaluation of fluorescence-based thermal shift assays for hit identification in drug discovery. Anal. Biochem. 2004, 332, 153-159. [CrossRef] 
55. Casu, B.; Grazioli, G.; Razi, N.; Guerrini, M.; Naggi, A.; Torri, G.; Oreste, P.; Tursi, F.; Zoppetti, G.; Lindahl, U. Heparin-like compounds prepared by chemical modification of capsular polysaccharide from E. coli K5. Carbohydr. Res. 1994, 263, 271-284. [CrossRef]

56. Yates, E.A.; Santini, F.; Guerrini, M.; Naggi, A.; Torri, G.; Casu, B. 1H and 13C NMR spectral assignments of the major sequences of twelve systematically modified heparin derivatives. Carbohydr. Res. 1996, 294, 15-27. [CrossRef]

57. Cavalcante, R.S.; Brito, A.S.; Palhares, L.C.; Lima, M.A. 2,3-Di-O-sulfo glucuronic acid: An unmodified and unusual residue in a highly sulfated chondroitin sulfate from Litopenaeus vannamei. Carbohydr. Polym. 2018, 183, 192-200. [CrossRef]

58. Vasconcelos, A.; Pomin, V.H. The Sea as a Rich Source of Structurally Unique Glycosaminoglycans and Mimetics. Microorganisms 2017, 5, 51. [CrossRef] [PubMed]

59. Pavão, M.S. Glycosaminoglycans analogs from marine invertebrates: Structure, biological effects, and potential as new therapeutics. Front. Cell. Infect. Microbiol. 2014, 4, 123. [CrossRef]

60. Dietrich, C.P.; Paiva, J.F.; Castro, R.A.B.; Chavante, S.F.; Jeske, W.; Fareed, J.; Gorin, P.A.J.; Mendes, A.; Nader, H.B. Structural features and anticoagulant activities of a novel natural low molecular weight heparin from the shrimp Penaeus brasiliensis. Biochim. Biophys. Acta Gen. Subj. 1999, 1428, 273-283. [CrossRef]

61. Medeiros, G.F.; Mendes, A.; Castro, R.A.B.; Baú, E.C.; Nader, H.B.; Dietrich, C.P. Distribution of sulfated glycosaminoglycans in the animal kingdom: Widespread occurrence of heparin-like compounds in invertebrates. Biochim. Biophys. Acta Gen. Subj. 2000, 1475, 287-294. [CrossRef]

62. Brito, A.S.; Cavalcante, R.S.; Palhares, L.C.; Hughes, A.J.; Andrade, G.P.V.; Yates, E.A.; Nader, H.B.; Lima, M.A.; Chavante, S.F. A non-hemorrhagic hybrid heparin/heparan sulfate with anticoagulant potential. Carbohydr. Polym. 2014, 99, 372-378. [CrossRef]

63. Chavante, S.F.; Brito, A.S.; Lima, M.; Yates, E.; Nader, H.; Guerrini, M.; Torri, G.; Bisio, A. A heparin-like glycosaminoglycan from shrimp containing high levels of 3-O-sulfated D-glucosamine groups in an unusual trisaccharide sequence. Carbohydr. Res. 2014, 390, 59-66. [CrossRef] [PubMed]

64. Chavante, S.F.; Santos, E.A.; Oliveira, F.W.; Guerrini, M.; Torri, G.; Casu, B.; Dietrich, C.P.; Nader, H.B. A novel heparan sulphate with high degree of $N$-sulphation and high heparin cofactor-II activity from the brine shrimp Artemia franciscana. Int. J. Biol. Macromol. 2000, 27, 49-57. [CrossRef]

65. Lima, M.; Rudd, T.; Yates, E. New Applications of Heparin and Other Glycosaminoglycans. Molecules 2017, 22, 749. [CrossRef] [PubMed]

66. Pomin, V.H. Holothurian fucosylated chondroitin sulfate. Mar. Drugs 2014, 12, 232-254. [CrossRef] [PubMed]

67. Spronk, S.A.; Carlson, H.A. The role of tyrosine 71 in modulating the flap conformations of BACE1. Proteins Struct. Funct. Bioinform. 2011, 79, 2247-2259. [CrossRef] [PubMed]

68. Rudd, T.R.; Guimond, S.E.; Skidmore, M.A.; Duchesne, L.; Guerrini, M.; Torri, G.; Cosentino, C.; Brown, A.; Clarke, D.T.; Turnbull, J.E.; et al. Influence of substitution pattern and cation binding on conformation and activity in heparin derivatives. Glycobiology 2007, 17, 983-993. [CrossRef] [PubMed]

69. Rudd, T.; Skidmore, M.; Guimond, S.; Holman, J.; Turnbull, J. The potential for circular dichroism as an additional facile and sensitive method of monitoring low-molecular-weight heparins and heparinoids. Thromb. Haemost. 2009, 102, 874-878. [PubMed]

70. Uniewicz, K.A.; Ori, A.; Xu, R.; Ahmed, Y.; Fernig, D.G.; Yates, E.A. Differential Scanning Fluorimetry measurement of protein stability changes upon binding to glycosaminoglycans: A rapid screening test for binding specificity. Anal. Chem. 2010, 82, 3796-3802. [CrossRef]

71. Niesen, F.H.; Berglund, H.; Vedadi, M. The use of differential scanning fluorimetry to detect ligand interactions that promote protein stability. Nat. Protoc. 2007, 2, 2212-2221. [CrossRef] [PubMed]

72. Van der Meer, J.Y.; Kellenbach, E.; van den Bos, L. From Farm to Pharma: An Overview of Industrial Heparin Manufacturing Methods. Molecules 2017, 22, 1025. [CrossRef] [PubMed]

(C) 2019 by the authors. Licensee MDPI, Basel, Switzerland. This article is an open access article distributed under the terms and conditions of the Creative Commons Attribution (CC BY) license (http://creativecommons.org/licenses/by/4.0/). 